ISSN 2227-7099

www.mdpi.com/journal/economies

Article

\title{
The Redistribution of Trade Gains When Income Inequality Matters
}

\section{Marco de Pinto}

Institute for Labour Law and Industrial Relations in the European Union (IAAEU), Trier University, Behringstr. 21, D-54296 Trier, Germany; E-Mail: depinto@iaaeu.de; Tel.: +49-651-201-4762

Academic Editor: Ralf Fendel

Received: 29 June 2015 / Accepted: 16 October 2015 / Published: 28 October 2015

\begin{abstract}
How does a redistribution of trade gains affect welfare when income inequality matters? To answer this question, we extend the [1] model to unionized labor markets and heterogeneous workers. As redistribution schemes, we consider unemployment benefits that are financed either by a wage tax, a payroll tax or a profit tax. Assuming that welfare declines in income inequality, we find that welfare increases up to a maximum in the case of wage tax funding, while welfare declines weakly (sharply) if a profit tax (payroll tax) is implemented. These effects are caused by the wage tax neutrality (due to union wage setting) and by a profit tax-induced decline in long-term unemployment. As a result, the government's optimal redistribution scheme is to finance unemployment benefits by a wage tax.
\end{abstract}

Keywords: trade liberalization; redistribution; income inequality; heterogeneity; trade unions

JEL classifications: F1; F16; H2 


\section{Introduction}

\subsection{Redistribution and Income Inequality}

Empirical evidence suggests that trade gains are not equally distributed over the economy and that some groups are even worse off. ${ }^{1}$ To ensure political support for international integration, it is thus argued that the government should redistribute income towards those individuals who are harmed by trade liberalization (see [5,6] for this line of reasoning). Based on this argument and on the public discussion about the possible implications, economists have analyzed the effects of different redistribution schemes in many different situations (see Section 1.2). One conclusion is that redistribution leads to a (partial) compensation for the harmed individuals, but is also accompanied by a reduction of welfare. Therefore, the best strategy for the government is to minimize the welfare loss for an ex ante-defined level of compensation (or vice versa).

A common assumption in this strand of literature is to exclusively measure welfare by income per capita (or likewise, output per capita). By definition, welfare mirrors the aggregate utility of individuals. Because individual utility in turn depends on the absolute level of income, this assumption can, at first glance, be justified. However, there is also strong empirical evidence that individuals have an aversion against income inequality, such that higher inequality reduces utility (see, for instance, [7-9]). This finding leads to some concerns about the validity of the assumption maintained in the literature. A more sophisticated measurement of welfare thus takes both income per capita and income inequality into account. Then, of course, it could be possible that redistribution enhances welfare, which also increases the government's policy options.

In this paper, we take up this argumentation and analyze the effects of redistribution policies when income inequality negatively affects welfare. To that end, we consider three different redistribution schemes. The government pays unemployment benefits (UB) to redistribute income towards the losers of trade liberalization, but UB are financed either by a wage tax, a payroll tax or a profit tax. For each redistribution scheme, the government seeks the welfare maximizing level of UB. By comparing maximized welfare levels, the optimal redistribution scheme at which welfare is highest can be determined. The advantage of this approach is that we can disentangle the effects of different financial forms of UB and are thus able to identify, with increased clarity, the mechanisms through which redistribution affects welfare.

Besides the consideration of income inequality, our paper has two further features. First, we implement both firm and worker heterogeneity, such that we are able to measure the effects of the redistribution schemes on inter-group inequality. Furthermore, heterogeneity itself could affect the outcomes of the redistribution schemes and should thus be explicitly taken into account. Second, we

1 The work by [2] shows, for instance, that low productive firms are harmed by trade liberalization. More specifically, they use data of French firms and find that trade liberalization leads to a substantial market exit of low productive firms. In addition, there is new evidence, provided, e.g., by [3,4], that the effects of trade liberalization are ability specific, favoring (harming) high-ability (low-ability) workers in terms of employment and wages. 
assume that labor markets are unionized. As such, we analyze how an empirically-relevant labor market institution influences the performances of the redistribution schemes. ${ }^{2}$

Our model builds on the studies by [11,12]. In these papers, the [1] model with heterogeneous firms is extended by worker heterogeneity (i.e., workers are different with respect to their abilities) and unionized labor markets. ${ }^{3}$ Furthermore, [11] incorporates a government sector with the policy instruments mentioned above. In the present paper, we extend their models by implementing a welfare function that takes income inequality into account. For concreteness, we assume that welfare depends positively on income per capita and negatively on the Gini coefficient as a standard measurement of income inequality (see $[15,16]$ for similar approaches). The government's optimization problem is to choose a value of UB that maximizes the welfare function subject to the government's budget constraint. Because of non-linearities in the budget constraint, we simulate the solution of the government's optimization problem using standard parameter values drawn from the relevant literature.

As our main results, we find that UB financed by a wage tax increase welfare up to the point where the welfare maximum is reached. If UB are financed by a profit tax (payroll tax), however, welfare decreases weakly (sharply). Therefore, we find that the government's optimal redistribution scheme is to finance UB by a wage tax. These results are, in particular, driven by three effects. First, an increase in the wage tax has no impact on aggregate variables. A higher wage tax reduces the individuals' fallback income (because this depends on the net expected wage in the economy). Since trade unions set wages as a markup over the fallback income, the wage c.p. decreases. However, the union wage markup depends positively on the wage tax rate because unions have an incentive to keep the net wage of their members constant. An increase of it thus implies that the wage c.p. shifts up. Both countervailing effects offset each other, which explains the wage tax neutrality. Therefore, only UB affect welfare by a decline in income per capita (because unions set higher wages, which causes the unemployment rate to rise) and (as intended) by a decline in income inequality. Since the former is modest for relatively low values of $\mathrm{UB}$, we find a positive effect on welfare.

Second, an increase in the profit tax rates raises the labor demand for low-ability workers. This is because higher profit tax rates make market entry less attractive, such that the number of firms declines. Competition hence decreases, and more low productive firms, which demand low-ability workers, are able to produce without a loss. As a consequence, income inequality c.p. declines. However, the average productivity of firms also declines, implying that employment and income per capita decrease. This effect is strong enough to cause welfare to decline, but because of the reduced long-term unemployment, this decline is relatively weak. Third, the payroll tax is neither neutral nor has (partial) positive effects. A higher payroll tax raises firms' marginal costs, such that labor demand and aggregate

2 As pointed out by [10], bargaining agreements are still an important determinant for wage setting, in particular in European countries. For instance, the union coverage rate in Europe is about $66 \%$.

3 Worker heterogeneity is also introduced by [13,14], who set up a free trade model with search and matching frictions. In contrast to our model, however, they assume that abilities are match-specific and independently distributed. Consequently, a worker's ability for a given match does not convey any information about his or her ability for other (future) matches. 
output decline. This reinforces the decline in income and mitigates the decline in income inequality due to UB. Hence, the decline in welfare is stronger compared to the profit tax case.

\subsection{Related Literature}

The aim of the present paper is to analyze the effects of different redistribution schemes on welfare, which in turn depends, inter alia, on income inequality. In this setting, redistribution leads to a more equal income distribution and may thus increase welfare. This prediction is in contrast to the majority of studies that investigate the consequences of redistribution policies after trade has been liberalized. This is because welfare is assumed to be unaffected by changes in income inequality.

The paper by [17] is a study in this spirit. The authors extend the [1] model to fair wages and implement a redistribution scheme that consists of an absolute per capita transfer to all (homogenous) individuals and a proportional profit tax. Welfare is defined as output per capita. In this setting, it can be shown that a tax constellation exists that equalizes income distribution without eliminating the gains from trade, measured by an increase in welfare, completely. In a similar study, [18] differ between managers and workers as a further source of heterogeneity. Despite the authors introducing a measurement for (inter-group and intra-group) income inequality, welfare is measured by output per capita. As a result, they show that UB financed by proportional income tax decrease welfare.

In the paper by [11], worker and firm heterogeneity are combined with unionized labor markets in order to analyze the effects of different redistribution schemes on welfare. Like this paper, he assumes that the government pays UB financed either by a wage tax, a payroll tax or a profit tax, but welfare is defined in the same way as in the aforementioned studies. As a result, he shows that all three redistribution schemes reduce welfare and thus destroy the gains from trade. At that point where welfare falls back to its autarky level, the government stops redistribution by assumption. Comparing the performances of the redistribution schemes, it turns out that the wage tax funding leads to the highest level of compensation before trade gains are destroyed. In this paper, we instead measure welfare as a combination of income level and income inequality, as stated before. In this respect, we can analyze the effects of redistribution policies on income inequality; something which is not done by [11]. ${ }^{4}$

Similar to us and in contrast to the literature, [21] assumes that income inequality enters negatively in the welfare function. He builds a model with firms as worker-entrepreneurs and unobservable agent heterogeneity. As redistribution schemes, he implements different tax forms and finds that the optimal redistribution policy in response to trade liberalization is ambiguous. Compared to the present paper, however, he neither considers UB as a redistribution instrument nor the influences of trade unions. As such, our paper analyzes different policy instruments and identifies different channels through which the performances of redistribution schemes are affected.

4 While the cited studies introduce (firm and/or worker) heterogeneity in their models, which is also done in our paper, there is a strand of literature that investigates the redistribution of trade gains without sources of heterogeneity. For instance, [19] find that commodity taxes compensate the losers and recover the trade gains in the case of perfect competitive labor markets. The work in [20] argues, however, that this result does not hold if labor market imperfections are considered. Assuming a binding minimum wage, and hence the existence of involuntary unemployment, they find that the compensation of the losers fully negates the gains from trade. 
The remainder of the paper is structured as follows. In Section 2, we present the setup of the open economy model and derive the partial, as well as the general equilibrium. In Section 3, we describe the government's optimization problem, while we present its numerical solution in Section 4. Section 5 concludes.

\section{Theoretical Framework}

\subsection{Model}

We consider an open economy model with two symmetric countries. The economy of each country consists of two sectors: a final goods sector, in which a homogeneous (non-tradable) good $Y$ is produced under perfect competition, and an intermediate goods sector, in which a continuum of differentiated (tradable) goods is produced under monopolistic competition (see [17,22] for a similar approach).

We assume that the final good is a CESaggregate of all of the available intermediate good varieties:

$$
Y=M_{t}^{\frac{1}{1-\sigma}}\left[\int_{v \in V} q(v)^{\frac{\sigma-1}{\sigma}} d v+\int_{v \in V} q_{i m}(v)^{\frac{\sigma-1}{\sigma}} d v\right]^{\frac{\sigma}{\sigma-1}},
$$

where $V$ denotes the mass of all potentially-available varieties $M_{t}$ and $\sigma$ stands for the elasticity of substitution between any two varieties $(\sigma>1) . q(v)$ and $q_{i m}(v)$ measure the demand for variety $v$ in the domestic market and in the foreign market, respectively. ${ }^{5}$ We choose $Y$ as the numéraire, which allows for the normalization of the corresponding price index: $P \equiv 1$. Profit maximization of the final goods producers yields the total demand function for variety $v$ :

$$
q_{t}(v)=q(v)+q_{i m}(v)=\frac{Y}{M_{t}}\left[(p(v))^{-\sigma}+\left(p_{i m}(v)\right)^{-\sigma}\right] .
$$

In the intermediate goods sector, there is a continuum of ex ante homogeneous firms that can enter the market by paying a fixed entry cost $f_{e}>0$ (measured in units of final goods and equal across firms). After $f_{e}$ is sunk, firms draw a productivity level $\phi$ from a given distribution, such that they are heterogeneous afterward (see [1]). As is common in the literature, we assume that productivities are Pareto distributed with $G_{\phi}(\phi)=1-\left(\phi_{\min } / \phi\right)^{k}\left(\phi \geq \phi_{\min } \equiv 1\right.$ and $\left.k>1\right)$. In addition to the entry costs, there are (non-sunk) fixed costs of production for the domestic market $f>0$ and for the export market $f_{x}>0$ (measured in units of final goods and equal across firms). We also assume that the economy is endowed with an exogenous number of heterogeneous individuals $\bar{L}$, who differ in their abilities $a_{j}$, $j=1, \ldots, \bar{L}$. These abilities are Pareto distributed with $G_{a}(a)=1-\left(a_{\min } / a\right)^{k}\left(a \geq a_{\min } \equiv 1\right)$, and individuals are assumed to know and maintain their ability levels at any point in time (see [12]).

Besides firms and individuals, we introduce the government as the third player into the economy. In accordance to [11], there are four variables that describe the government's actions. On the expenditure

5 The specification of the CES aggregator rules out external scale effects; a well-understood mechanism through which free trade influences aggregate output. This assumption is made because we want to focus as clearly as possible on the effects of trade unions, as well as firm and worker heterogeneity for the implications of different redistribution schemes (see [22] for a similar line of reasoning). 
side, the government pays (individual-specific) UB $B_{j}$. On the revenue side, three kinds of taxes are available: (i) a proportional wage tax $T_{w}$ paid by all employed individuals; (ii) a proportional payroll $\operatorname{tax} T_{p w}$ paid by all operating firms $M$; and (iii) a proportional profit tax $T_{\pi}$ also paid by the firms. The corresponding tax rates are $t_{w} \in[0,1], t_{p w} \in[0,1]$ and $t_{\pi} \in[0,1]$.

The timing of our model is as follows (see [12] for a similar approach):

1. Firms draw their productivity and decide whether to enter the domestic market and, additionally, whether to export varieties abroad. In the case of production, firms post vacancies at no cost.

2. Individuals apply for the jobs, and each firm randomly hires some workers from the pool of applicants.

3. The firms' employees form a monopoly trade union at the firm level, which sets the wage on behalf of their members.

4. Given the wage set by the union, the firm can readjust the employment decision of Stage 2, i.e., its right-to-manage privilege.

The rationale behind our assumption that the firms' employees form a trade union is the following (see [12]). At the second stage, each firm has already hired a fraction of workers from the pool of its applicants. These employees choose to deal with the firm either individually or as a collective group. Each worker knows that s/he can be replaced by another applicant at no cost (the number of applicants in the pool is greater than employment). Therefore, the threat to delay production or to bring production to a standstill is not credible at the individual level. Only as a (sufficiently large) group is such a threat credible. Consequently, a trade union is formed at the firm level, and the initial workers are the union members. We stick to the special case of a monopoly union, because this simplifies our model without affecting the key results.

Note that the determination of the partial and the general equilibrium, to which we look in the following subsections, is very similar to the one pursued by [12], as well as by [11]. Therefore, we refer to these studies for a more detailed description of the solution strategy.

\subsection{Partial Equilibrium}

In the partial equilibrium, all players take the behavior of the others as given, i.e., macroeconomic variables are considered as exogenous. To calculate the partial equilibrium, we solve the aforementioned game by backwards induction.

\subsubsection{Employment and Prices (Stage 4)}

Consider a firm with productivity $\phi$, which produces the variety $v$. The firm can either solely sell the variety in the domestic market or can additionally export it to the foreign market. We first look at the firm's optimal behavior in the domestic market and take up the endogenous export decision afterward (see Section 2.2.3). The firm's production technology is given by:

$$
q=h \phi \bar{a}
$$

where $h$ denotes the number of employees and $\bar{a}$ represents their average ability level. 
To establish a link between the firm's productivity and the worker's ability, we assume that the firm sets a (firm-specific) minimum quality requirement according to (see [12]):

$$
a_{l}=\phi^{\alpha} \quad \text { with } \quad \alpha \geq 0 .
$$

This assumption has two consequences. First, it implies that workers with abilities lower than $a_{l}$ are not hired because their marginal product of labor is zero (or even negative because of complementarities). Second, the minimum quality requirement $a_{l}$ is increasing in the firm's productivity $\phi$. Intuitively, high productive firms have a more complex production process and, thus, need workers with higher abilities than low productive firms. Parameter $\alpha$ denotes the sensitivity of changes in $a_{l}$ in response to variations in productivity. Note that we use Equation (3) as a short-cut for the more sophisticated approach of $[13,14]$, in which the ability threshold is endogenously determined by implementing a costly screening technology. Using the short-cut has the advantage that we can derive a firm-specific demand for workers (and their abilities) without overloading our model by implementing search and matching frictions.

Moreover, there is also an upper bound of abilities for each firm. If the firm offers a wage rate $w$, there will be a marginal worker with ability $a_{z}$ who is indifferent between unemployment and employment at the firm. The indifference condition is given by:

$$
w^{n e t} \equiv\left(1-t_{w}\right) w=b_{z}\left(a_{z}\right), \quad \frac{\partial b}{\partial a}>0,
$$

with $b_{z}$ denoting the marginal worker's reservation wage, which is increasing in $a .{ }^{6}$ Thus, the firm can only employ workers with abilities $a \leq a_{z}$ because workers with $a>a_{z}$ do not even apply for a job. Summing up, the ability interval of the firm's workers is given by $\left[a_{l}(\phi), a_{z}\left(w^{n e t}\right)\right]$. The average (or expected) ability level of the firm's workforce reads:

$$
\bar{a}=\Gamma_{1} \frac{\left(a_{l}\right)^{1-k}-\left(a_{z}\right)^{1-k}}{\left(a_{l}\right)^{-k}-\left(a_{z}\right)^{-k}} \quad \text { with } \quad \Gamma_{1} \equiv \frac{k}{k-1} .
$$

Net profits are defined by $\pi^{n e t} \equiv\left(1-t_{\pi}\right)\left(r-\left(1+t_{p w}\right) h w-f\right)$, and revenues read:

$$
r=q p=q^{\kappa}\left(Y / M_{t}\right)^{1 / \sigma}, \quad \kappa \equiv 1-\frac{1}{\sigma},
$$

where the last equality follows by using the domestic demand for the produced variety. The parameter $\kappa$ $(0<\kappa<1)$ denotes the degree of competitiveness in the differentiated good sector. Profit maximizing implies $\partial r / \partial h=\left(1+t_{p w}\right) w$, which determines the optimal level of employment. The optimal price is a constant mark-up $1 / \kappa$ over marginal costs:

$$
p=\frac{1}{\kappa} \frac{\left(1+t_{p w}\right) w}{\phi \bar{a}} .
$$

Note that net profits can also be written as $\pi^{n e t}=\left(1-t_{\pi}\right)(r / \sigma-f)$.

6 In Section 2.2.2, we analytically show that $\partial b / \partial a>0$ holds. Intuitively, high-ability workers are able to work in high productive firms, which pay higher wages. This raises their expected wage rates and, thus, their reservation wages. 


\subsubsection{Wages and Applications (Stage 3 and 2)}

At the third stage, the monopoly union determines the wage rate $w$. Because union members are heterogeneous with respect to their abilities, the union maximize the expected utility $E U$ of its median member $m$ (see [23]):

$$
E U_{m}=\frac{h}{h^{0}}\left(1-t_{w}\right) w+\left(1-\frac{h}{h^{0}}\right) b_{m}
$$

with $b_{m}$ denoting the reservation wage (fallback income) of the median member. $h^{0}$ stands for the number of initial workers employed at the second stage and, thus, measures union membership. This also implies that the union's median member and the firm's median worker coincide. The maximization problem is restricted by the firm's right to manage employment at the fourth stage, such that the union has to take the condition $\partial r / \partial h=\left(1+t_{p w}\right) w$ into account. As a result, the wage $w$ is a mark-up $\theta /\left(1-t_{w}\right)$ over the median member's reservation wage:

$$
w=\frac{\theta}{1-t_{w}} b_{m} \quad \text { with } \quad \theta \equiv \frac{1}{\kappa}>1 .
$$

To explicitly calculate the wage rate, we have to determine the reservation wage of the median member. For that purpose, consider worker $j$ with ability $a_{j}$. Using the step-by-step derivation presented by [12], we find that the worker $j$ 's reservation wage is given by:

$$
b_{j}=u B_{j}+(1-u)\left(1-t_{w}\right) \bar{w}_{j}
$$

with $u$ denoting the unemployment rate and $\bar{w}_{j}$ being the outside wage, which is defined as $j$ 's expected wage rate in the economy. UB of worker $j$ are modeled as a constant share of his/her net outside wage:

$$
B_{j}=s\left(1-t_{w}\right) \bar{w}_{j}
$$

with $0 \leq s \leq 1$ denoting the replacement ratio that is set by the government. ${ }^{7}$

Regarding the outside wage, we adopt a conventional assumption about its determinants and assume that $\bar{w}_{j}$ is a combination of worker characteristics (internal forces) and economy-wide labor market variables (external forces). ${ }^{8}$ In our context, the most plausible internal force is the ability $a_{j}$ of worker $j$. By facilitating access to better jobs, a high ability level improves the chance to be hired by a firm with a high average ability of its workforce. A high average ability, in turn, increases the size of the rent, which accrues to the trade union via a higher wage rate. The external force is described by the wage prevailing in the general equilibrium $\widehat{w}$. This choice is supported by the result that in a world with homogeneous workers, the outside wage and the equilibrium wage coincide (see [27]). Formally, we assume (see also [12]):

$$
\bar{w}_{j}=a_{j}^{\omega} \widehat{w}^{1-\omega} \quad 0 \leq \omega \leq 1
$$

7 Equation (11) fits two empirical regularities regarding the design of the UB in most countries (see [24] for evidence). First, UB are related to the individuals' average income. Second, individuals pay tax on UB, either since their calculation is based on net average income or since the payment itself (based on gross earnings) is taxable.

8 For some empirical evidence, compare [25,26]. 
with $\omega$ and $1-\omega$ as the weight of the internal force, respectively external force. ${ }^{9}$ Inserting Equations (12) and (11) into Equation (10), as well as setting $j=m$ leads to the reservation wage of the union's median member:

$$
b_{m}=\left(1-t_{w}\right)(1-u(1-s)) a_{m}^{\omega} \widehat{w}^{1-\omega} .
$$

The ability level of the median member $a_{m}$ can be calculated by taking the job application process at Stage 2 into account. Workers collect information about job vacancies and apply for them. Information gathering is costless, such that all individuals have perfect knowledge of all job descriptions, which include the minimum quality requirement $a_{l}$ and a (net) wage offer $w^{\text {net }} .{ }^{10}$ Because the marginal costs of applications are zero by assumption, the optimal strategy of a worker with ability $a$ is to apply for all jobs with a minimum quality requirement $a_{l} \leq a$ and a (net) wage offer no less than his or her reservation wage, $w^{\text {net }} \geq b(a)$. This delivers a well-defined pool of applicants, such that each firm obtains a full distribution of abilities with the limits $\left[a_{l}, a_{z}\right]$. The firm randomly draws workers from this pool until $h^{0}$ is reached. ${ }^{11}$

The ability level of the firm's marginal worker, $a_{z}=\theta^{1 / \omega} a_{m}$, can be obtained by inserting Equation (13) with $m=z$ into Equation (4), as well as using Equation (9) and again Equation (13). Because workers' abilities are Pareto-distributed within the interval $\left[a_{l}, a_{z}\right]$, the ability of the median member/worker is given by:

$$
a_{m}=2^{1 / k}\left[\left(a_{z}\right)^{-k}+\left(a_{l}\right)^{-k}\right]^{-1 / k}
$$

Inserting Equations (3) and (14) into the expression for the ability of the marginal worker, we obtain $a_{z}=A^{1 / k} \phi^{\alpha}$ with $A \equiv 2 \theta^{k / \omega}-1$. Thus, we can rewrite the ability of the median member as $a_{m}=$ $\theta^{-\frac{1}{\omega}} A^{\frac{1}{k}} \phi^{\alpha}$. Substituting this result into Equation (13) and combining with Equation (9), we find the explicit solution for the wage rate:

$$
w=A^{\omega / k}(1-u(1-s)) \widehat{w}^{1-\omega} \phi^{\alpha \omega} .
$$

\subsubsection{Production and Export Decision (Stage 1)}

At the first stage, firms draw their productivity level $\phi$ and have to decide whether production is valuable given $\phi$. Firms will produce for the domestic market if and only if net profits are non-negative: $\pi^{n e t}(\phi) \geq 0$. There is a marginal firm that is just indifferent between production and exit, i.e., $\pi^{\text {net }}\left(\phi^{*}\right)=0$, where $\phi^{*}$ is referred to as cutoff productivity. To sell varieties abroad, firms have to

9 The ad hoc specification of $\bar{w}_{j}$ is needed because we have to deal with the simultaneity between the application process and the expected wage rate. On the one hand, a worker applies for a job if the wage offer is no less than the reservation wage (depending on the outside wage). On the other hand, the expected wage rate depends on the number and characteristics of jobs for which the worker applies. Thus, the decision to apply is determined jointly with the expected wage rate.

10 Notably, we assume that vacancy posting is costless to avoid further sources of labor market frictions.

11 Because the structure of the game is common knowledge, both firms and workers perfectly foresee the wage-employment outcome of Stages 3 and 4 , and $h^{0}=h$ holds. This implies that the threat to readjust employment in Stage 4 is credible. Neither the worker/union nor the firm have an incentive to deviate from the anticipated wage-employment combination. Note further that the pool of applicants at Stage 2 is characterized by a mass of workers (with $a \in\left[a_{l}, a_{z}\right]$ ). This implies that $\bar{a}$ cannot be changed by adjusting the employment decision at Stage 4 as long as the firm randomly chooses workers from the application pool (which we assume in our model). 
bear variable iceberg costs $\tau \geq 1$ besides the fixed cost $f_{x}$. Exporting presumes that net export profits are non-negative: $\pi_{x}^{\text {net }}(\phi) \geq 0$. There is also a marginal exporting firm with productivity $\phi_{x}^{*}$ for which $\pi_{x}^{n e t}\left(\phi_{x}^{*}\right)=0$ holds.

In line with [1], only a fraction of firms engage in exporting. For $\phi \geq \phi_{x}^{*}$, firms are exporters and produce for both the domestic and the foreign market. For $\phi^{*} \leq \phi<\phi_{x}^{*}$, firms produce for the domestic market only. Note further that profit maximization of the exporters yields $p_{x}=\tau p, q_{x}=\tau^{-\sigma} q$, $h_{x}=\tau^{1-\sigma} h$ and $r_{x}=\tau^{1-\sigma} r$. Maximized net export profits are given by $\pi_{x}^{n e t}=\left(1-t_{\pi}\right)\left(r_{x} / \sigma-f_{x}\right)$. Thus, the export variables can be expressed as a function of the domestic variables.

\subsection{General Equilibrium}

\subsubsection{The Representative Firm}

The aggregate variables can be calculated in the standard way (see $[1,17,22]$ ) and read: $P=p\left(\widetilde{\phi}_{t}\right) \equiv 1, Y=M_{t} q\left(\widetilde{\phi}_{t}\right), R=M_{t} r\left(\widetilde{\phi}_{t}\right)$ and $\Pi^{\text {net }}=\left(1-t_{\pi}\right) M_{t} \pi\left(\widetilde{\phi}_{t}\right)$, where $R$ and $\Pi^{\text {net }}$ denote aggregate revenues and net profits, respectively, and $\widetilde{\phi}_{t}$ is the total average productivity level of all active firms in a country. For aggregate employment, we get:

$$
\begin{gathered}
H=M_{t} h\left(\widetilde{\phi}_{t}\right) \cdot \xi_{1}^{\alpha \omega / \beta} \xi_{2} \Psi, \quad \text { with } \beta \equiv(\sigma-1)(1+\alpha-\alpha \omega)>0, \\
\xi_{1} \equiv \frac{k}{k-\beta}, \quad \xi_{2} \equiv \frac{k-\beta}{k-\beta+\alpha \omega}, \quad \Psi \equiv \frac{1+\tau^{1-\sigma} \chi^{1+\frac{\alpha \omega-\beta}{k}}}{1+\chi},
\end{gathered}
$$

with $\chi(0 \leq \chi \leq 1)$ denoting the ex ante probability of being an exporter. Note that we assume $k-\beta>0$, which implies $\xi_{1}>1$ and $0<\xi_{2}<1$. The total number of all active firms (and thus, the number of all available varieties) in a country is given by $M_{t}=M+M_{x}=M(1+\chi)$, where $M_{x}$ represents the number of exporters and the subscript $t$ indicates the sum of domestic and export activities.

The aggregate variables have an important property (see [1]): the aggregate levels of $P, Y, R, \Pi$ and $H$ are identical to what they would be if the economy were endowed with $M_{t}$ identical firms with productivity $\widetilde{\phi}_{t}$. Therefore, we treat the firm with productivity $\widetilde{\phi}_{t}$ as the representative firm for the economy. For notational convenience, we denote the respective variables of the representative firm by $\widetilde{p}$, $\widetilde{q}, \widetilde{h}, \widetilde{r}, \widetilde{w}$ and $\widetilde{\pi}$.

By following the step-by-step derivation of [22], we can calculate the total average productivity level of all active firms as:

$$
\widetilde{\phi}_{t}=\widetilde{\phi}\left[\frac{1}{1+\chi}\left(1+\chi \tau^{1-\sigma}\left(\frac{\widetilde{\phi}_{x}}{\widetilde{\phi}}\right)^{\beta}\right)\right]^{1 / \beta}
$$


where $\widetilde{\phi}$ is the average productivity of all domestic firms and $\widetilde{\phi}_{x}$ is the average productivity of exporting firms. ${ }^{12}$ Due to the Pareto distribution, we can compute $\widetilde{\phi}=\xi_{1}^{1 / \beta} \phi^{*}$ and $\widetilde{\phi}_{x}=\xi_{1}^{1 / \beta} \phi_{x}^{*}$. As shown in Appendix A.1, we can additionally determine the productivity of the marginal exporting firm as: $\phi_{x}^{*}=$ $\tau^{\frac{\sigma-1}{\beta}}\left(f_{x} / f\right)^{1 / \beta} \phi^{*}$. Inserting this term into the last expression, substituting the result into Equation (17) and using $\chi=\left(1-G_{\phi}\left(\phi_{x}^{*}\right)\right) /\left(1-G_{\phi}\left(\phi^{*}\right)\right)=\left(\phi^{*} / \phi_{x}^{*}\right)^{k}$, we find that $\widetilde{\phi}_{t}=\widetilde{\phi}$ if and only if $f_{x}=f$. In order to simplify our model, we stick to this case in the following and, hence, find:

$$
\widetilde{\phi}_{t}=\widetilde{\phi}=\xi_{1}^{1 / \beta} \phi^{*}
$$

For a discussion on this assumption, see [22].

\subsubsection{Free Entry}

As in [1], we assume that there is an unbounded pool of firms that can enter the market, i.e., paying the entry costs $f_{e}$ and drawing a productivity level. Free entry implies that the present value of average net profits of active firms equals $f_{e}$ in equilibrium. This is described by the free entry condition:

$$
\left(1-G_{\phi}\left(\phi^{*}\right)\right) \frac{\bar{\pi}_{t}^{\text {net }}}{\delta}=f_{e}
$$

where $1-G_{\phi}\left(\phi^{*}\right)$ is the probability that firms equipped with a certain productivity start production and $\delta$ stands for the exogenous death probability of firms. $\bar{\pi}_{t}^{\text {net }}$ denotes average net profits, which are defined as: $\bar{\pi}_{t}^{n e t} \equiv \Pi^{\text {net }} / M$. Using the expressions for $\Pi^{\text {net }}$ and $M$ introduced above, we can rewrite Equation (19) and arrive at:

$$
\widetilde{\pi}=\left(\phi^{*}\right)^{k} \frac{\delta f_{e}}{\left(1-t_{\pi}\right)(1+\chi)} .
$$

From the definition of the marginal firm, we find that $r\left(\phi^{*}\right)=\sigma f$ holds, which we refer to as the zero profit cutoff condition. Using this, we can show that the revenue of the representative firm is given by (see Appendix A.2 for the proof): $\widetilde{r}=\xi_{1} \sigma f$. Inserting into the (gross) profit function, we hence obtain:

$$
\widetilde{\pi}=\left(\xi_{1}-1\right) f
$$

which shows that the profit of the representative firm depends only on model parameters. This is a standard result in the corresponding literature and driven by the assumption of Pareto-distributed productivities.

Combining Equations (20) and (21), we can solve for the equilibrium cutoff productivity:

$$
\phi^{*}\left(t_{\pi}\right)=\left[\left(1-t_{\pi}\right)(1+\chi)\left(\xi_{1}-1\right) \frac{f}{\delta f_{e}}\right]^{1 / k},
$$

with $\chi=\tau^{-k /(\alpha(1-\omega)+1)}$.

12 The difference between the two averages $\widetilde{\phi}_{t}$ and $\widetilde{\phi}$ can be explained by the interplay between the lost-in-transit effect (i.e., goods vanish en route because of iceberg transport costs) and the export-selection effect (i.e., exporting firms are the most productive in the economy). Compared to the domestic level $\widetilde{\phi}$, the former shrinks total average productivity $\widetilde{\phi}_{t}$, while the latter increases it. 
As all other firms in the market, the marginal firm also sets a minimum quality requirement, which we denote by $a_{l}^{*}$. Since no operating firm has a lower productivity, $a_{l}^{*}$ can be interpreted as the minimum quality requirement for the whole economy. With Equation (3), we obtain:

$$
a_{l}^{*}\left(t_{\pi}\right)=\left[\phi^{*}\left(t_{\pi}\right)\right]^{\alpha} .
$$

This leads to a segregation of the labor force $\bar{L}$ of the economy. For workers with $a<a_{l}^{*}$, abilities are not sufficient to gain any job, as no operating firm on the market will demand abilities below $a_{l}^{*}$. Those workers are referred to as long-term unemployed persons. Their number is denoted by $L^{l}$, and the corresponding unemployment rate equals one: $u^{l}=1$. Workers with $a \geq a_{l}^{*}$ could gain a job because there is potentially labor demand for those abilities. Therefore, we call these individuals active ${ }^{13}$ workers. $L$ stands for the number of active workers, and $u \equiv 1-H / L<1$ denotes the respective unemployment rate. Using the probabilities $\operatorname{Pr}\left(a<a_{l}^{*}\right)=1-\left(a_{l}^{*}\right)^{-k}$ and $\operatorname{Pr}\left(a>a_{l}^{*}\right)=\left(a_{l}^{*}\right)^{-k}$ as weights yields the total unemployment rate:

$$
\bar{u}=1-\left(a_{l}^{*}\right)^{-k} \frac{H}{L} .
$$

Notably, long-term unemployed persons also receive UB. In contrast to the UB of active workers, we eliminate the worker-specific component. Since a person with an ability below $a_{l}^{*}$ has no opportunity to get a job in the economy, her/his outside wage drops to zero, and according to Equation (11), the UB would be zero, as well. To avoid this, we assume that the UB of long-term unemployed persons is a constant share $s$ of the net equilibrium wage rate instead of the worker-specific net outside wage:

$$
B^{l}=s\left(1-t_{w}\right) \widehat{w} \quad \forall a \in\left[1, a_{l}^{*}\right) .
$$

\subsubsection{Labor Market}

To determine the labor market equilibrium, we make use of the concepts of wage-setting and price-setting schedules; see $[12,28]$. The wage-setting schedule visualizes the "target" real wage, i.e., the wage intended by trade unions. The price-setting schedule represents the "feasible" real wage, i.e., the wage firms are willing to concede to the workers. In the general equilibrium, the real income claims of workers are consistent with those of firms. If the target real wage exceeds (falls short of) the feasible real wage, we will observe an upward (downward) wage-price spiral implying an increase (decrease) in unemployment.

The feasible real wage $w_{P S}$ is determined by using the pricing rule of the representative firm, which is given by Equation (7). Setting $p=\widetilde{p}=1, \phi=\widetilde{\phi}_{t}$ and $w=\widetilde{w}$, we find after some rearrangements:

$$
\widetilde{w}_{P S}\left(t_{p w}, t_{\pi}\right) \equiv \widetilde{w}\left(t_{p w}, t_{\pi}\right)=\frac{1}{1+t_{p w}} \kappa \widetilde{a}\left(t_{\pi}\right) \cdot \widetilde{\phi}_{t}\left(t_{\pi}\right),
$$

with $\widetilde{a}$ denoting the average ability of the representative firm's workforce. Inserting Equation (3) with $\phi=\widetilde{\phi}_{t}$ and $\widetilde{a}_{z}=A^{1 / k} \widetilde{\phi}_{t}^{\alpha}$ into Equation (5), we obtain:

$$
\widetilde{a}\left(t_{\pi}\right)=\Gamma_{1} \Gamma_{2}\left[\widetilde{\phi}_{t}\left(t_{\pi}\right)\right]^{\alpha} \quad \text { with } \quad \Gamma_{2} \equiv \frac{A-A^{1 / k}}{A-1} .
$$

13 "Active" means that these workers have a positive employment probability. Nevertheless, active workers can also be unemployed. 
As a result, $w_{P S}$ is independent of (un)employment due to our assumptions about linear technology and the constant price elasticity of product demand. Thus, Equation (26) unilaterally determines the wage rate in the general equilibrium: $\widehat{w}\left(t_{p w}, t_{\pi}\right)=w_{P S}\left(t_{p w}, t_{\pi}\right)$.

Regarding the target real wage $w_{W S}$, we immediately obtain from Equation (15):

$$
w_{W S}\left(s, t_{p w}, t_{\pi}\right)=[A(\theta)]^{\omega / k}(1-u(1-s))\left[\widehat{w}\left(t_{p w}, t_{\pi}\right)\right]^{1-\omega}\left[\widetilde{\phi}_{t}\left(t_{\pi}\right)\right]^{\alpha \omega} .
$$

In the labor market equilibrium, we have $w_{P S}=w_{W S}=\widehat{w}$. The endogenous variable that fulfills this equilibrium condition is the unemployment rate of active workers $u$. Thus, we obtain:

$$
u\left(s, t_{p w}, t_{\pi}\right)=\frac{1-\Gamma_{3}\left(t_{p w}\right) \cdot\left[\widetilde{\phi}_{t}\left(t_{\pi}\right)\right]^{\omega}}{1-s} \text { with } \quad \Gamma_{3}\left(t_{p w}\right) \equiv\left(\frac{\kappa \Gamma_{1} \Gamma_{2}}{\left(1+t_{p w}\right) A^{1 / k}}\right)^{\omega} .
$$

The number of long-term unemployed persons $L^{l}=\operatorname{Pr}\left(a<a_{l}^{*}\right) \bar{L}$ and the number of active workers $L=L-L^{l}$ can be calculated as:

$$
\begin{gathered}
L^{l}\left(t_{\pi}\right)=\left(1-\xi_{1}^{\alpha k / \beta}\left[\widetilde{\phi}\left(t_{\pi}\right)\right]^{-\alpha k}\right) \bar{L}, \\
L\left(t_{\pi}\right)=\xi_{1}^{\alpha k / \beta}\left[\widetilde{\phi}\left(t_{\pi}\right)\right]^{-\alpha k} \bar{L} .
\end{gathered}
$$

Using the definition of $u$, we find for aggregate employment $H$ :

$$
H\left(s, t_{p w}, t_{\pi}\right)=\left[1-u\left(s, t_{p w}, t_{\pi}\right)\right] L\left(t_{\pi}\right) .
$$

Finally, we can insert Equations (18), (23) and (31) into Equation (24) to compute the equilibrium aggregate unemployment rate $\bar{u}$ :

$$
\bar{u}\left(s, t_{p w}, t_{\pi}\right)=1-\frac{H\left(s, t_{p w}, t_{\pi}\right)}{\bar{L}} .
$$

\subsubsection{Goods Market}

Given the labor market clearing conditions, we are able to compute aggregate output in the general equilibrium. Using Equations (2) and (16), we get $Y=M_{t} \widetilde{q}=M_{t} \widetilde{h} \widetilde{a} \bar{\phi}_{t}=H \widetilde{a} \widetilde{\phi}_{t} /\left(\xi_{1}^{\alpha \omega / \beta} \xi_{2} \Psi\right)$. Inserting Equation (27) leads to:

$$
Y\left(s, t_{p w}, t_{\pi}\right)=\frac{\Gamma_{1} \Gamma_{2}}{\xi_{1}^{\alpha \omega / \beta} \xi_{2} \Psi} H\left(s, t_{p w}, t_{\pi}\right) \cdot\left[\widetilde{\phi}_{t}\left(t_{\pi}\right)\right]^{1+\alpha} .
$$

Thus, variations of $H$ are translated into changes of $Y$ one to one. Note that we normalize total labor force to one without any loss of generality: $\bar{L} \equiv 1$. Hence, $Y$ can also be interpreted as output per capita.

To complete the goods market equilibrium, we can calculate the number of firms in the market by using $Y\left(s, t_{p w}, t_{\pi}\right)=R\left(s, t_{p w}, t_{\pi}\right)=(1+\chi) M \widetilde{r}$ and obtain: $M\left(s, t_{p w}, t_{\pi}\right)=Y\left(s, t_{p w}, t_{\pi}\right) /((1+$ $\left.\chi) \xi_{1} f \sigma\right)$. 


\section{The Government}

\subsection{Objective Function}

Suppose that, without any policy intervention, trade is liberalized by a reduction of variable iceberg $\operatorname{costs} \tau$. This trade liberalization induces the well-known firm-selection effect (see [1]) and raises income per capita. We define the income increase as gains from trade. However, trade liberalization is not a Pareto improvement. For instance, the least productive firms are driven out of the market and are thus harmed by trade openness. In addition, the firm selection also implies a worker-selection effect in our setting. Due to the reduction of the number of firms with a relatively low productivity, the labor demand for low-ability workers decreases, and the number of long-term unemployed workers rises (see [11,12] for a more extensive intuition).

Observing the unequal distribution of trade gains, the government decides to interfere in the market. The basic aim of the government is to redistribute trade gains in order to benefit the losers of trade liberalization. In doing so, the government regulates the payment of UB by setting the replacement ratio $s$, which is thus the policy variable. To determine which level of $s$ the government should choose, it is necessary to define an objective function of the government.

We assume that the government considers the welfare function as its objective function. In contrast to the standard approach in the literature, we take up the empirical observation that the utility of individuals depends on the income level, but also on the income distribution. Hence, welfare should be approximated by a functional form that captures both relative and absolute income terms. Welfare functions of this type are introduced, e.g., by $[15,16]$. We follow the latter and assume that welfare is given by:

$$
V=I \cdot \Theta^{-\gamma}
$$

with $I$ denoting aggregate income per capita and $\Theta$ representing the Gini coefficient as the standard measure of income inequality. $\gamma \in[0,1]$ measures the income inequality aversion and can be interpreted as an inequality elasticity that indicates the percentage change in income for a $1 \%$ rise in inequality in order to hold utility constant. Note that if $\Theta$ increases, income inequality rises and welfare declines. ${ }^{14}$

\subsection{Income and Income Inequality}

Before we describe the government's optimization problem, which must also include the budget constraint, it is useful to calculate $I$ and $\Theta$. To that end, note that we focus on the part of income that is disposable for consumption. Observing the free entry condition Equation (19), it is evident that aggregate net profits are used to finance (sunk) market entry costs paid by firms in equilibrium. Thus, $\Pi^{\text {net }}$ has no effect on consumption, and we ignore this income component in the following (see [22] for a similar approach).

14 As also stated by [16], the functional form of the welfare function given by Equation (35) was introduced by [29]. As shown by [30], it fits quite well with the empirical evidence on individuals' inequality aversion. Hence, we use a welfare specification that is relatively simple (and therefore highly tractable), is established in the literature and seems not to be at odds with empirical findings. 
Aggregate income is thus defined as:

$$
I \equiv B_{a g g r}+W-T_{w}-T_{p w}-T_{\pi}
$$

with $B_{\text {aggr }}$ being aggregate UB and $W$ denoting aggregate wage income. Because of the prevalence of monopolistic competition and the CES technology, the latter is a constant share $\kappa$ of aggregate revenues:

$$
W\left(s, t_{p w}, t_{\pi}\right)=\kappa R\left(s, t_{p w}, t_{\pi}\right)
$$

Tax revenues are given by:

$$
\begin{gathered}
T_{w}\left(s, t_{w}, t_{p w}, t_{\pi}\right)=t_{w} W\left(s, t_{p w}, t_{\pi}\right), \\
T_{p w}\left(s, t_{p w}, t_{\pi}\right)=t_{p w} W\left(s, t_{p w}, t_{\pi}\right), \\
T_{\pi}\left(s, t_{p w}, t_{\pi}\right)=t_{\pi} \Pi=t_{\pi} M_{t} \pi\left(\widetilde{\phi}_{t}\right)=t_{\pi}(1+\chi)\left(\xi_{1}-1\right) f M\left(s, t_{p w}, t_{\pi}\right) .
\end{gathered}
$$

The aggregate UB are defined as $B_{\text {aggr }} \equiv B^{l}+B^{u}$, with $B^{l}$ and $B^{u}$ representing the aggregate payment of UB to long-term unemployed individuals and unemployed active workers, respectively. These are given by:

$$
\begin{gathered}
B^{l}\left(s, t_{w}, t_{p w}, t_{\pi}\right)=s\left(1-t_{w}\right) \widehat{w} L^{l} \\
B^{u}\left(s, t_{w}, t_{p w}, t_{\pi}\right)=s\left(1-t_{w}\right) \widehat{w} \frac{L^{u}}{1-G_{a}\left(a_{l}^{*}\right)} \int_{a_{l}^{*}}^{\infty} a^{\omega} d G_{a}(a),
\end{gathered}
$$

where $L^{u}=L-H$ denotes the number of unemployed active workers. Note that variables on the right-hand side depend on the government's parameters (see the result of the general equilibrium), but we abstain from an indication due to notational convenience. To sum up, aggregate income depends, inter alia, on the government's policy variable and on the tax rates: $I=I\left(s, t_{w}, t_{p w}, t_{\pi}\right)$. Because we have normalized the number of all individuals at unity, $I$ measures also aggregate income per capita.

To compute the Gini coefficient $\Theta$, we first have to determine the Lorenz curve (see [18] for the general analytical approach). Therefore, we combine cumulative income with the proportion of individuals $\eta$ receiving this income. There are three sources of income for individuals in our model: $B^{l}$, $B^{u}$ and $W^{n e t} \equiv\left(1-t_{w}-t_{p w}\right) W$. Moreover, we have to be aware that a subgroup of firms engage in exporting and, thus, pay wages from a different profile than firms serving only the domestic market. Thus, the Lorenz curve is divided into four segments with boundaries $c_{1}, c_{2}, c_{3}$ and one. Formally, the Lorenz curve is given by:

$$
Q\left(\eta, s, t_{w}, t_{p w}, t_{\pi}\right) \equiv\left\{\begin{array}{lll}
Q^{1}\left(\eta, s, t_{w}, t_{p w}, t_{\pi}\right) & \text { if } & 0 \leq \eta<c_{1} \\
Q^{2}\left(\eta, s, t_{w}, t_{p w}, t_{\pi}\right) & \text { if } & c_{1} \leq \eta<c_{2} \\
Q^{3}\left(\eta, s, t_{w}, t_{p w}, t_{\pi}\right) & \text { if } & c_{2} \leq \eta<c_{3} \\
Q^{4}\left(\eta, s, t_{w}, t_{p w}, t_{\pi}\right) & \text { if } & c_{3} \leq \eta \leq 1
\end{array} .\right.
$$

In detail, we have (see Appendix A.3 for the step-by-step derivation and the definition of the new variables):

$$
Q^{1}\left(\eta, s, t_{w}, t_{p w}, t_{\pi}\right)=\frac{I^{1}}{I}=\frac{s\left(1-t_{w}\right) \widehat{w} \bar{L} \eta}{I}
$$




$$
\begin{gathered}
Q^{2}\left(\eta, s, t_{w}, t_{p w}, t_{\pi}\right)=\frac{I^{2}}{I}=\frac{\bar{I}^{1}+s\left(1-t_{w}\right) \widehat{w}^{1-\omega} L^{u} \Delta_{1} \Omega_{1}(\eta)}{I}, \\
Q^{3}\left(\eta, s, t_{w}, t_{p w}, t_{\pi}\right)=\frac{I^{3}}{I}=\frac{\bar{I}^{2}+W^{n e t} \Delta_{2} \Omega_{2}(\eta)}{I}, \\
Q^{4}\left(\eta, s, t_{w}, t_{p w}, t_{\pi}\right)=\frac{I^{4}}{I}=\frac{\bar{I}^{3}+W^{n e t} \Delta_{2}\left(\chi+\chi^{\frac{k-\beta}{k}}\right) \Omega_{3}(\eta)}{I},
\end{gathered}
$$

where we again omit the indication that variables on the right-hand side depend on policy parameters.

Given the Lorenz curve, we can compute the Gini coefficient from:

$$
\Theta\left(s, t_{w}, t_{p w}, t_{\pi}\right)=1-2 \int_{0}^{1} Q\left(\eta, s, t_{w}, t_{p w}, t_{\pi}\right) d \eta .
$$

\subsection{Optimization Problem}

The government maximizes its objective function given by Equation (34) over the replacement ratio $s$. However, the optimization is restricted by the budget constraint. To disentangle the effects of the wage, payroll and profit tax, we assume that the government can only implement one of these tax forms. This assumption allows for comparing three different redistribution schemes with respect to their impacts on welfare.

If UB are financed by a wage tax, i.e., $t_{w}>0$ and $t_{p w}=t_{\pi}=0$, the optimization problem is given by:

$$
\begin{gathered}
\max _{s} V\left(s, t_{w}\right)=I\left(s, t_{w}\right) \Theta\left(s, t_{w}\right)^{-\gamma} \\
\text { s.t. } \quad B_{a g g r}\left(s, t_{w}\right)=T_{w}\left(t_{w}\right) .
\end{gathered}
$$

If UB are financed by a payroll tax, i.e., $t_{p w}>0$ and $t_{w}=t_{\pi}=0$, the optimization problems reads:

$$
\begin{gathered}
\max _{s} V\left(s, t_{p w}\right)=I\left(s, t_{p w}\right) \Theta\left(s, t_{p w}\right)^{-\gamma} \\
\text { s.t. } \quad B_{a g g r}\left(s, t_{p w}\right)=T_{p w}\left(s, t_{p w}\right) .
\end{gathered}
$$

If UB are financed by a profit tax, i.e., $t_{\pi}>0$ and $t_{w}=t_{p w}=0$, we obtain:

$$
\begin{gathered}
\max _{s} V\left(s, t_{\pi}\right)=I\left(s, t_{\pi}\right) \Theta\left(s, t_{\pi}\right)^{-\gamma} \\
\text { s.t. } \quad B_{a g g r}\left(s, t_{\pi}\right)=T_{\pi}\left(s, t_{\pi}\right) .
\end{gathered}
$$

To solve the government's optimization problem, we must rearrange the budget constraint to find a functional form between the respective marginal tax rate (dependent variable) and the replacement ratio $s$ (policy variable). Then, we would be able to insert the result into the government's objective function, such that $V$ depends only on $s$ and on the model's parameters. However, we cannot solve the budget constraints in this way due to non-linearities, and thus, we cannot find an explicit solution of the optimization problems. Therefore, we have to solve our model numerically, which we approach in the next section. ${ }^{15}$

15 In a similar study, [31] also investigates the impact of different redistribution schemes on welfare. This study, however, sticks to the assumptions that only exporting firms have to pay a profit tax and that budget is ex ante neutral, i.e., repercussion effects of policy instruments on the budget constraint are ruled out. 


\section{Numerical Solution}

\subsection{Calibration}

The choice of parameter values is based on standard practice in the literature. Parameter values referring to the Melitz model are taken from calibrations by $[32,33]$. The value of the shape parameter of the Pareto distribution is chosen in accordance with the structural estimation by [34]. Table 1 summarizes the parameter values for monthly time periods.

Table 1. Parameter values used in calibration.

\begin{tabular}{cccc}
\hline Parameter & Value & Interpretation & Source \\
\hline$\tau_{0}, \tau_{1}$ & $1.6,1.3$ & Iceberg trade costs & {$[33]$} \\
$\sigma$ & 3.8 & Elasticity of substitution & {$[32]$} \\
$k$ & 5.2 & Shape parameter Pareto & {$[34]$} \\
$f$ & 1.77 & Fixed costs & {$[32]$} \\
$f_{e}$ & 39.57 & Entry costs & {$[32]$} \\
$\delta$ & 0.025 & Firms' death probability & {$[33]$} \\
$\omega$ & 0.8 & Weight of workers' abilities & {$[35]$} \\
$\alpha$ & 0.25 & Quality requirement & \\
$\gamma$ & 0.2 & Inequality aversion & {$[36]$} \\
\hline
\end{tabular}

There are three parameters that are specific to our model, namely $\omega, \alpha$ and $\gamma$, such that the choice of their values have to be justified in more detail. The parameter $\omega$, which measures the weight of the abilities in the wage determination, has only been estimated in a few studies. The work by [35] claims that 84 percent of wage differences across industries are explained by individual fixed effects, while only 16 percent can be traced back to industry dummies. The strong weight of individual characteristics in the wage determination is confirmed by, for instance, $[25,26]$. Hence, a value of $\omega=0.8$ does not seem at odds with the empirical literature.

Unfortunately, to the best of our knowledge, there is no empirical estimation for the parameter $\alpha$ that captures the strength of the minimum quality requirements (or equivalently, the strength on which firms with different productivities demand workers with different abilities). According to [11], we set $\alpha=0.25$, implying that the minimum quality requirement is relatively weak. Thus, the quality of the firm's management, $\phi$, is significantly higher than the ability level of its least productive worker, $\phi^{\alpha}$, which (at least in our opinion) should be the case in nearly all firms.

Concerning the parameter of inequality aversion, $\gamma$, which can be interpreted as inequality elasticity (see above), there is relatively good empirical evidence. The work by [15] uses an experimental design to show that the value of inequality aversion is in the interval between 0.09 and 0.22 . The work by [36] measures income inequality by an empirical analysis with data from the GSOEP (German Socio-Economic Panel) between 1985 and 1998 and obtains a value about 0.2. Thus, we set $\gamma=0.2$. 


\subsection{UB Financed by a Wage Tax}

The solution of the government's optimization problem in the case of wage tax funding is illustrated by Figure 1.

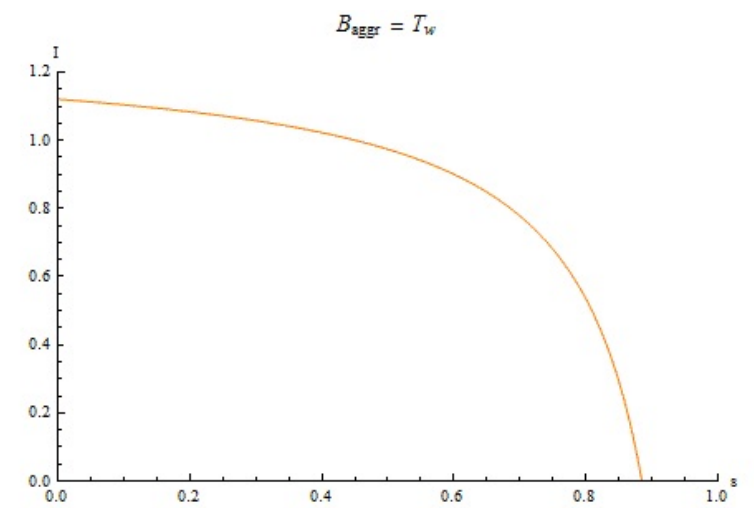

(a)

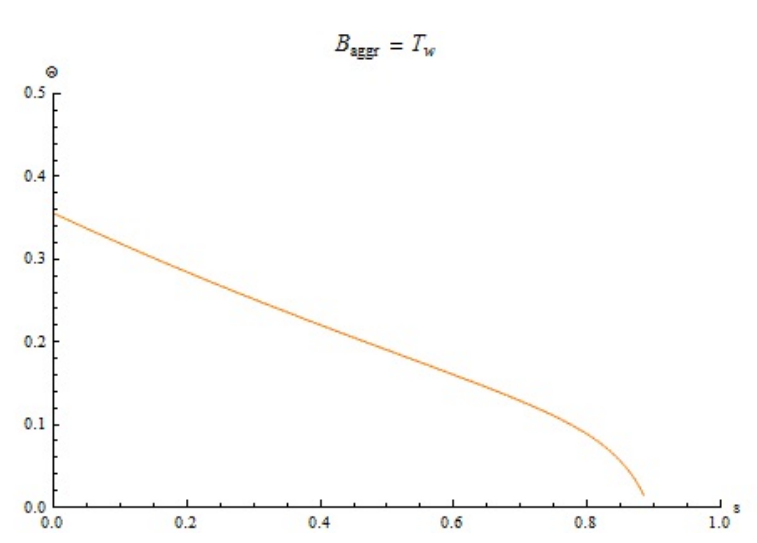

(b)

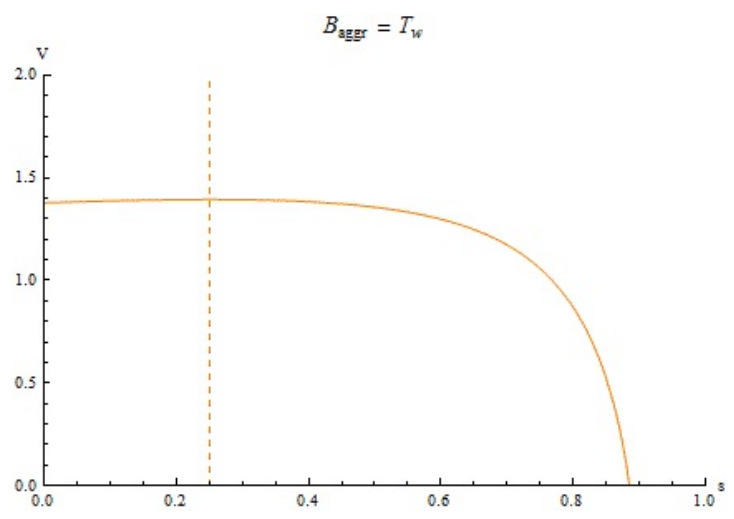

(c)

Figure 1. UB (unemployment benefits) financed by a wage tax. (a) income; (b) Gini coefficient; (c) welfare.

Result 1. Suppose that the government finances UB by a wage tax. Then, (i) income per capita decreases, (ii) the Gini coefficient decreases and (iii) the welfare path is hump-shaped with the maximum at $s=s_{t_{w}}^{*}$.

The decline in income per capita is driven by the decline in aggregate output per capita $Y$. If $s$ and thus UB increase, the monopoly unions' target real wage at any given level of employment rises because of an increasing fallback income of the median member (see Equation (28)). The firm's answer to such a rise in its marginal costs is an increase in its profit-maximizing price. Product and labor demand drop, and the number of employed workers decreases (see Equation (32)). The decline in $H$ leads to a reduction of aggregate output $Y$, which reduces wage income and, thus, $I$. We call this channel the UB effect on $I$ in the following argumentation. In addition, we have to take into account the consequences of the UB funding, i.e., here the wage tax. However, as pointed out in more detail by [11], the wage tax is neutral for the aggregate variables. This is because a higher wage rate leads to an increase in the wage mark-up 
(see Equation (9)) and a decrease in the fallback income (see Equation (10)), which exactly offset each other. Hence, the target real wage is unaffected by variations in $t_{w} .{ }^{16}$

The decline in the Gini coefficient occurs because paying UB increases the income of so far unemployed workers. This effect dominates possible negative consequences due to the decrease in aggregate employment, such that income inequality monotonously decreases. We call this mechanism the UB effect on $\Theta$ in the following. Note that due to wage tax neutrality for aggregate variables, $t_{w}$ has a negligible impact on the Gini coefficient. Only UB, c.p., decline in $t_{w}$ (see Equations (41) and (42)), which is, however, overcompensated by the increase in $s$.

Observing the hump-shaped welfare path, it is obviously the case that the decline in income inequality dominates the decrease in income per capita for $s<s_{t_{w}}^{*}$, such that welfare increases until the maximum is reached. This result is relatively robust because the wage tax neutrality, the sign of the UB effect on $I$ and the sign of the UB effect on $\Theta$ are parameter independent. In Appendix A.4, we have shown that for different values of trade costs and inequality aversion, the existence of a welfare maximum holds nearly in all cases, but of course, its location varies.

\subsection{UB Financed by a Payroll Tax}

If UB are financed by a payroll tax, the solution of the government's optimization problem can be illustrated by Figure 2 .

Result 2. Suppose that the government finances $U B$ by a payroll tax. Then, (i) income per capita decreases, (ii) the Gini coefficient decreases and (iii) welfare declines. Optimization yields the corner solution $s=s_{t_{p w}}^{*}=0$.

The decline in $I$ is driven by the UB effect on $I$, on the one hand, and by the non-neutral effect of the payroll tax on the other hand. A rise of the payroll tax increases the firm's marginal costs, implying an increase in the profit-maximizing price. Therefore, product demand, revenues and profits decline. The number of firms operating in the market shrinks, and thus, aggregate employment declines. The reduction of $H$ leads to a one-to-one decrease in aggregate output (see Equation (34)), such that income per capita decreases. Relative to the wage tax funding, note that the decline in $I$ is relatively strong because the pay roll tax has negative effects on $H$ and $Y .{ }^{17}$

16 This result is heavily driven by our modeling approach regarding UB (see Equation (11)). If, for instance, UB are based on gross expected income, the neutrality result between $w$ and $t_{w}$ vanishes. We argue, however, that a tax collection on $\mathrm{UB}$ is the empirically-relevant case. In addition, simulations suggest that setting $t_{w}=0$ in Equation (11) will only lead to a quantitatively low effect of $t_{w}$ on $w$, in particular for low values of the wage tax rate. These simulations are available upon request.

17 Note further that we allow only values of $s$ for which Laffer efficiency holds, i.e., an increase in tax rates must not imply a decline in tax revenues. 


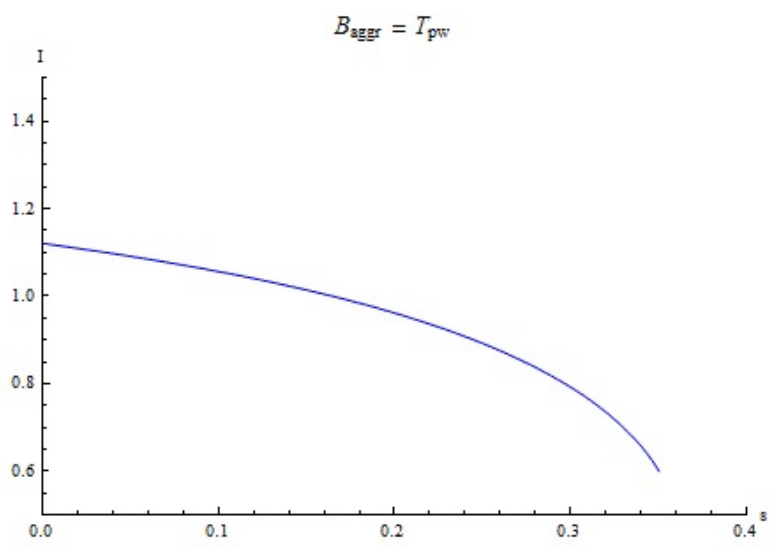

(a)

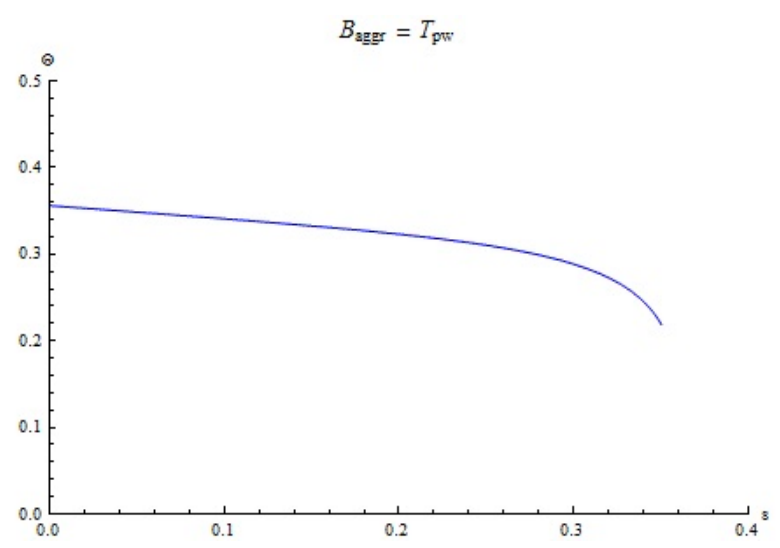

(b)

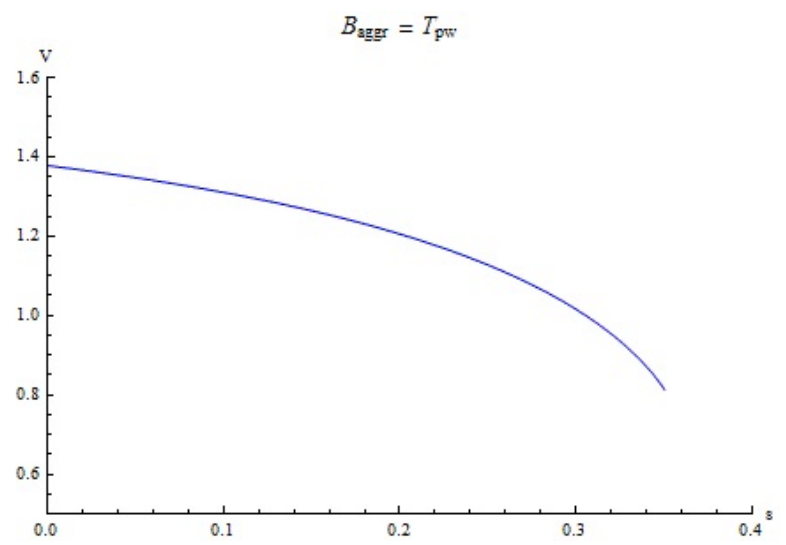

(c)

Figure 2. UB financed by a payroll tax. (a) income; (b) Gini coefficient; (c) welfare.

Looking at the income distribution, the UB effect on $\Theta$ (which reduces income inequality) interacts with the impact of the payroll tax on $\Theta$. As stated above, aggregate employment falls, which c.p. increases income inequality (at least for the allowed values of $s$ ). This effect is mitigated by a decline in the equilibrium wage rate, which is caused by the firms' price increase (see Equation (26)). ${ }^{18}$ With respect to net, the payroll tax increases income inequality. Combining the latter with the UB effect on $\Theta$, it is evidently from Figure 2 that there is still a reduction of $\Theta$, but compared to the wage tax funding (where only the UB effect on $\Theta$ is at work), the reduction is less pronounced.

The relatively weak decrease in income inequality and the relatively strong decrease in income per capita explain that welfare unambiguously declines in $s$. It is thus welfare-maximizing for the government to abstain from redistribution. This result is relatively robust, because the sign of the payroll tax effect on income per capita and income inequality is parameter independent (see Appendix A.4).

18 The reduction in $\widehat{w}$ passes through to wage setting at the firm level because of the implied decrease in the outside wage (see Equation (12)). Thus, unions set c.p. a lower wage rate. If $w$ decreases, the number of workers employed by active firms rises, but there is also the decline in goods demand because of the payroll tax mentioned above, which reduces $h$. In the equilibrium, these two effects exactly offset each other, and employment per firm remains constant. 


\subsection{UB Financed by a Profit Tax}

In the case that UB are financed by a profit tax, the solution of the government's optimization problem can be illustrated by Figure 3 .

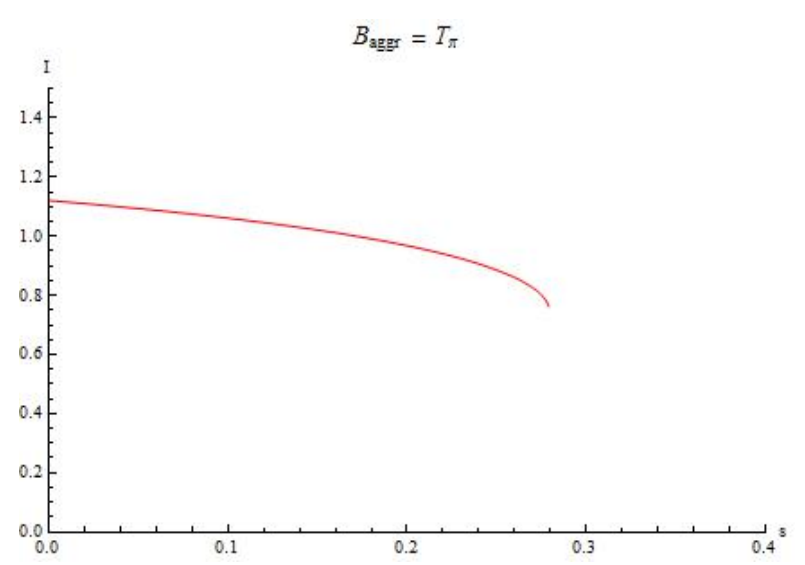

(a)

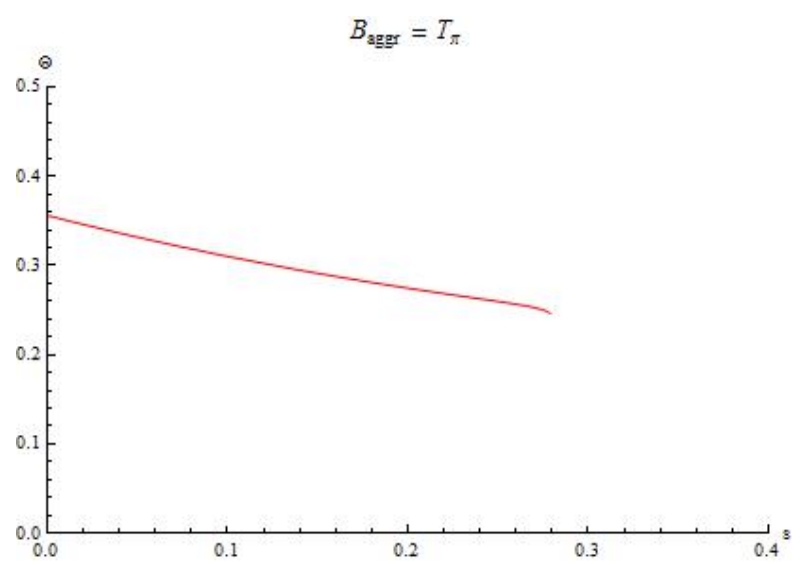

(b)

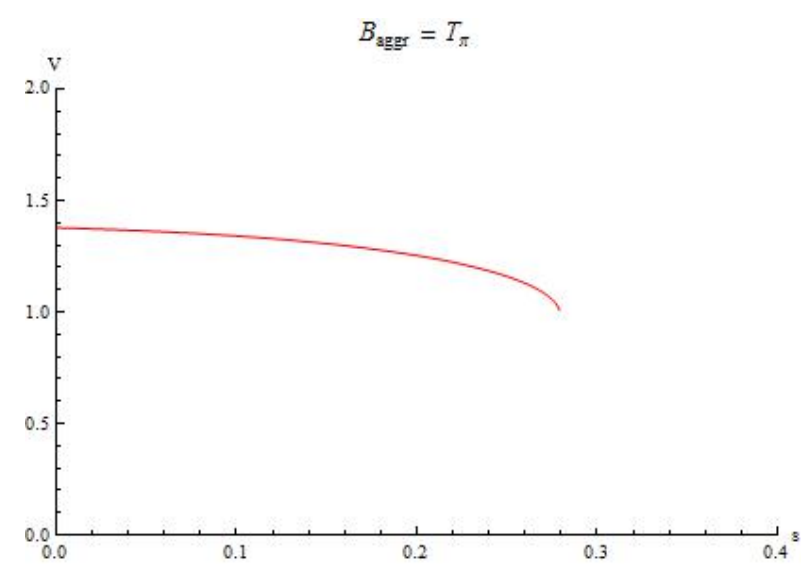

(c)

Figure 3. UB financed by a profit tax. (a) income; (b) Gini coefficient; (c) welfare.

Result 3. Suppose that the government finances $U B$ by a profit tax. Then, (i) income per capita decreases, (ii) income inequality decreases and (iii) welfare declines. Optimization yields the corner solution $s=s_{t_{\pi}}^{*}=0$.

The reduction of $I$ can be explained by the UB effect on $I$ and by the negative effect of a profit tax on the cutoff productivity (see Equation (22)). Intuitively, an increase in $t_{\pi}$ implies a decline of expected net profits, and market entry becomes thus less attractive. The number of firms in the market decreases, which lowers competition for the still operating firms. As a consequence, firms with lower productivity can survive in the market, which is mirrored by a decline of $\phi^{*}$. This has two implications. On the one hand, there are more firms demanding low-ability workers, which reduces the number of long-term unemployed persons (see Equation (30)); aggregate employment and output increase. On the other hand, the average productivity of operating firms falls (see Equation (18)). As a consequence, marginal costs increase, leading to a reduction of the feasible real wage and forcing down the employment level $H$, as 
well as the aggregate output $Y$. It is evident from Figure 3 that the negative effects due to UB and the decreasing $\widetilde{\phi}_{t}$ dominate the positive effects of the lower number of long-term unemployed persons, such that $Y$ and, hence, $I$ decline.

Turning to income distribution, the UB effect on $\Theta$ interacts with the consequences of the profit tax for income inequality. On the one hand, income inequality c.p. increases because the average productivity of operating firms and, hence, employment decline. On the other hand, the number of long-term unemployed individuals falls, implying a decrease in income inequality. Moreover, the composition of firms varies. If $t_{\pi}$ rises, $\phi_{x}^{*}$ shifts up, and the number of exporting firms decreases. As a consequence, the employment share of high-wage firms, i.e., exporters, goes down, leading to lower inequality among employed workers, which results in a reduction of $\Theta$. As a result, income inequality monotonously declines.

As shown in Figure 3, however, the decline in income per capita dominates the decline in the Gini coefficient for all values of UB. Therefore, welfare unambiguously decreases. Note, however, that this decline is weaker compared to the payroll tax funding because of the positive employment effect for low-ability workers. Note further that the strength of this effect is parameter-dependent. For example, if we would assume a substantially higher value of $k$, the reduction of long-term unemployment becomes stronger, and welfare could increase at least for low values of $s$. For different values of $\tau$ and $\gamma$, however, this result is relatively robust (see Appendix A.4).

Our results lead to the following conclusion:

Result 4. The government's optimal redistribution policy is to finance UB by a wage tax and to set $s=s_{t_{w}}^{*}$.

Recall that this result is caused by the wage tax neutrality (due to the union's wage setting), which leads to a relatively weak (strong) decline in income per capita (in income inequality) if UB are financed by a wage tax.

\section{Summary}

How does the redistribution of trade gains affect welfare when income inequality matters? To answer this question, we set up a general equilibrium model with heterogeneous firms and monopolistic competition in the goods market as done by [1]. However, we extend this approach by worker heterogeneity and unionized labor markets in order to analyze how these empirically-relevant features affect the performances of the redistribution policy. As redistribution schemes, we consider UB that are financed either by a wage tax, a payroll tax or a profit tax.

As our main result, we have shown that redistribution can indeed increase welfare if income inequality is taken into account. This is in strong contrast to the corresponding literature, where income inequality is neglected and the government can only choose a redistribution scheme to minimize the welfare loss for an ex ante-defined level of compensation. In our framework, it turns out that the wage tax funding increases welfare until the maximum is reached. This result is driven by the fact that the wage tax is neutral for aggregate variables because of the unions' wage setting. In addition, our simulations have indicated that welfare decreases if UB are financed by a profit tax or payroll tax, but that the welfare decline is relatively moderate in the former case. This is because long-term unemployment declines if 
a profit tax is implemented, which c.p. reduces income inequality. Therefore, we can conclude that the features of our model, worker heterogeneity and trade unions, have to be well considered when evaluating the effects of redistribution systems.

The government's optimal redistribution scheme is, at least in our setting, to finance UB by a wage tax and set the replacement ratio in such a manner that the welfare maximum is reached. Obviously, our predictions are limited, in the sense that we only look at UB as a redistribution instrument. In future research, our approach can be extended to a policy mix, where in addition to UB, employment subsidies, wage subsidies or progressive tax forms are also considered.

\section{Acknowledgments}

I gratefully acknowledge helpful comments from Jochen Michaelis, Rainer Vosskamp, Jürgen Meckl, Laszlo Goerke, Sam Kortum, Klaus Wälde, as well as from the participants at the conferences in Kassel, Trier, Mainz and Leuven. I would also like to thank Christoph Tasto for his excellent research assistance.

\section{Conflicts of Interest}

The authors declare no conflict of interest.

\section{A. Appendix}

\section{A.1. Derivation of the Export Cutoff Productivity}

Recall that maximized profits of the domestic and export market are given by, respectively: $\pi(\phi)=$ $r(\phi) / \sigma-f$ and $\pi_{x}(\phi)=\tau^{1-\sigma} r(\phi) / \sigma-f_{x}$, where we used $r_{x}=\tau^{1-\sigma} r$. For the marginal firm in the domestic and in the export market, we hence find:

$$
\begin{gathered}
\pi\left(\phi^{*}\right)=0 \Leftrightarrow r\left(\phi^{*}\right)=\sigma f, \\
\pi_{x}\left(\phi_{x}^{*}\right)=0 \Leftrightarrow r\left(\phi_{x}^{*}\right)=\tau^{\sigma-1} \sigma f_{x} .
\end{gathered}
$$

Moreover, we can calculate the relation of revenues between any two firms with productivities $\phi_{1}$ and $\phi_{2}, \phi_{2}>\phi_{1}$, as:

$$
\frac{r\left(\phi_{2}\right)}{r\left(\phi_{1}\right)}=\left(\frac{\phi_{2}}{\phi_{1}}\right)^{\beta} .
$$

Setting $\phi_{2}=\phi_{x}^{*}$ and $\phi_{1}=\phi^{*}$, we can combine Equations (A.1)-(A.3) to obtain:

$$
\left(\frac{\phi_{x}^{*}}{\phi^{*}}\right)^{\beta}=\tau^{\sigma-1} \frac{f_{x}}{f},
$$

which proves that $\phi_{x}^{*}=\tau^{\frac{\sigma-1}{\beta}}\left(f_{x} / f\right)^{1 / \beta} \phi^{*}$.

\section{A.2. Derivation of the Revenue of the Representative Firm}

Setting $\phi_{2}=\widetilde{\phi}_{t}$ and $\phi_{1}=\phi^{*}$, we find from Equation (A.3):

$$
\widetilde{r}\left(\widetilde{\phi}_{t}\right)=\left(\frac{\widetilde{\phi}_{t}}{\phi^{*}}\right)^{\beta} r\left(\phi^{*}\right) .
$$


Inserting Equation (A.1), as well as Equation (18), we obtain $\widetilde{r}=\xi_{1} \sigma f$.

\section{A.3. Derivation of the Lorenz Curve}

\section{A.3.1. First Segment}

The cumulative income of long-term unemployed individuals with an ability level up to $\check{a} \in\left[1, a_{l}^{*}\right)$ is given by:

$$
I^{1}(\check{a})=s\left(1-t_{w}\right) \widehat{w} \frac{L^{l}}{G_{a}\left(a_{l}^{*}\right)} \int_{1}^{\check{a}} d G_{a}(a) .
$$

The proportion of individuals that receives this income is given by:

$$
\eta(\check{a})=\frac{1}{\bar{L}} \frac{L^{l}}{G_{a}\left(a_{l}^{*}\right)} \int_{1}^{\check{a}} d G_{a}(a) .
$$

Combining Equations (A.6) and (A.7) to eliminate $\check{a}$, we find:

$$
I^{1}\left(\eta, s, t_{w}, t_{p w}, t_{\pi}\right)=s\left(1-t_{w}\right) \widehat{w} \bar{L} \eta
$$

such that the first segment of the Lorenz curve is given by:

$$
Q^{1}\left(\eta, s, t_{w}, t_{p w}, t_{\pi}\right)=\frac{I^{1}\left(\eta, s, t_{w}, t_{p w}, t_{\pi}\right)}{I}
$$

The boundary of the first segment is defined by $c_{1} \equiv \eta\left(\check{a}=a_{l}^{*}\right)=L^{l} / \bar{L}$. Evaluating Equation (A.8) at $\eta=c_{1}$, we obtain:

$$
I^{1}\left(c_{1}\right) \equiv \bar{I}^{1}=B^{l}
$$

which implies $Q^{1}\left(c_{1}\right)=\bar{I}^{1} / I<1$.

\section{A.3.2. Second Segment}

The cumulative income of unemployed individuals, i.e., long-term unemployed persons and unemployed active workers with an ability level up to $\check{a} \in\left[a_{l}^{*}, \infty\right]$, is given by:

$$
I^{2}(\check{a})=\bar{I}^{1}+s\left(1-t_{w}\right) \widehat{w}^{1-\omega} \frac{L^{u}}{1-G_{a}\left(a_{l}^{*}\right)} \int_{a_{l}^{*}}^{\check{a}} a^{\omega} d G_{a}(a) .
$$

Using the Pareto distribution, we can rewrite the last expression as:

$$
\begin{gathered}
I^{2}(\check{a})=\bar{I}^{1}+s\left(1-t_{w}\right) \widehat{w}^{1-\omega} L^{u} \Delta_{1}\left(1-\left(\frac{\check{a}}{a_{l}^{*}}\right)^{\omega-k}\right), \\
\Delta_{1} \equiv \frac{\left(a_{l}^{*}\right)^{\omega-k}}{1-G_{a}\left(a_{l}^{*}\right)} \frac{k}{k-\omega} .
\end{gathered}
$$

The proportion of individuals that receives this income is given by:

$$
\eta(\check{a})=\frac{L^{l}}{\bar{L}}+\frac{1}{\bar{L}} \frac{L^{u}}{1-G_{a}\left(a_{l}^{*}\right)} \int_{a_{l}^{*}}^{\check{a}} d G_{a}(a) .
$$


Using the Pareto distribution, we can rewrite the last expression as:

$$
\eta(\check{a})=\frac{L^{l}}{\bar{L}}+\frac{L^{u}}{\bar{L}}\left(1-\left(\frac{\check{a}}{a_{l}^{*}}\right)^{-k}\right) .
$$

Combining Equations (A.11) and (A.12) to eliminate $\breve{a}$, we find:

$$
\begin{gathered}
I^{2}\left(\eta, s, t_{w}, t_{p w}, t_{\pi}\right)=\bar{I}^{1}+s\left(1-t_{w}\right) \widehat{w}^{1-\omega} L^{u} \Delta_{1} \Omega_{1}(\eta), \\
\Omega_{1}(\eta) \equiv 1-\left(1-\left(\eta-\frac{L^{l}}{\bar{L}}\right) \frac{\bar{L}}{L^{u}}\right)^{\frac{k-\omega}{k}},
\end{gathered}
$$

such that the second segment of the Lorenz curve is given by:

$$
Q^{2}\left(\eta, s, t_{w}, t_{p w}, t_{\pi}\right)=\frac{I^{2}\left(\eta, s, t_{w}, t_{p w}, t_{\pi}\right)}{I}
$$

The boundary of the second segment is defined by $c_{2} \equiv \eta(\check{a} \rightarrow \infty)=\left(L^{l}+L^{u}\right) / \bar{L}$. Evaluating Equation (A.13) at $\eta=c_{2}$, we obtain:

$$
I^{2}\left(c_{2}\right) \equiv \bar{I}^{2}=B_{\text {aggr }},
$$

which implies $Q^{2}\left(c_{2}\right)=\bar{I}^{2} / I<1$.

\section{A.3.3. Third Segment}

The cumulative income of all unemployed individuals and employed active workers at firms with a productivity level up to $\check{\phi} \in\left[\phi^{*}, \phi_{x}^{*}\right)$, i.e., firms producing for the domestic market only, is given by:

$$
I^{3}(\check{\phi})=\bar{I}^{2}+\left(1-t_{w}-t_{p w}\right) \frac{M}{1-G_{\phi}\left(\phi^{*}\right)} \kappa \int_{\phi^{*}}^{\check{\phi}} r(\phi) d G_{\phi}(\phi),
$$

with $\kappa r(\phi)=w(\phi) h(\phi)$. Using Equation (A.3) with $\phi_{2}=\phi$ and $\phi_{1}=\widetilde{\phi}_{t}$, as well as $W^{n e t}=\left(1-t_{w}-\right.$ $\left.t_{p w}\right) \kappa M_{t} \widetilde{r}$, we obtain:

$$
I^{3}(\check{\phi})=\bar{I}^{2}+W^{n e t} \frac{\widetilde{\phi}_{t}^{-\beta}}{1-G_{\phi}\left(\phi^{*}\right)} \frac{M}{M_{t}} \int_{\phi^{*}}^{\check{\phi}} \phi^{\beta} d G_{\phi}(\phi) .
$$

Employing the Pareto distribution, we can rewrite the last expression as:

$$
\begin{gathered}
I^{3}(\check{\phi})=\bar{I}^{2}+W^{n e t} \Delta_{2}\left(1-\left(\frac{\check{\phi}}{\phi^{*}}\right)^{\beta-k}\right), \\
\Delta_{2} \equiv(1+\chi)^{-1} .
\end{gathered}
$$

The proportion of individuals that receives this income is given by:

$$
\eta(\check{\phi})=\frac{L^{l}+L^{u}}{\bar{L}}+\frac{1}{\bar{L}} \frac{M}{1-G_{\phi}\left(\phi^{*}\right)} \int_{\phi^{*}}^{\check{\phi}} h(\phi) d G_{\phi}(\phi) .
$$


Using $h(\phi)=\left(\phi / \widetilde{\phi}_{t}\right)^{\beta-\alpha \omega} \widetilde{h}$ and the Pareto distribution, we can rewrite the last expression as:

$$
\begin{gathered}
\eta(\check{\phi})=\frac{L^{l}+L^{u}}{\bar{L}}+\frac{H}{\bar{L}} \Delta_{3}\left(1-\left(\frac{\check{\phi}}{\phi^{*}}\right)^{\beta-\alpha \omega-k}\right) . \\
\Delta_{3} \equiv\left(1+\chi^{\frac{k+\alpha \omega}{k}}\right)^{-1} .
\end{gathered}
$$

Combining Equations (A.16) and (A.17) to eliminate $\check{\phi}$, we find:

$$
\begin{gathered}
I^{3}\left(\eta, s, t_{w}, t_{p w}, t_{\pi}\right)=\bar{I}^{2}+W^{n e t} \Delta_{2} \Omega_{2}(\eta), \\
\Omega_{2}(\eta) \equiv 1-\left(1-\left(\eta-\frac{L^{l}+L^{u}}{\bar{L}}\right) \frac{\bar{L}}{H} \frac{1}{\Delta_{3}}\right)^{\frac{k-\beta}{k+\alpha \omega-\beta}},
\end{gathered}
$$

such that the third segment of the Lorenz curve is given by:

$$
Q^{3}\left(\eta, s, t_{w}, t_{p w}, t_{\pi}\right)=\frac{I^{3}\left(\eta, s, t_{w}, t_{p w}, t_{\pi}\right)}{I}
$$

The boundary of the third segment is defined by $c_{3} \equiv \eta\left(\check{\phi}=\phi_{x}^{*}\right)=\left(L^{l}+L^{u}+\Delta_{4} H\right) / \bar{L}$, with:

$$
\Delta_{4} \equiv \frac{1-\chi^{\frac{k+\alpha \omega-\beta}{k}}}{\Delta_{3}}
$$

Evaluating Equation (A.18) at $\eta=c_{3}$, we obtain:

$$
I^{3}\left(c_{3}\right) \equiv \bar{I}^{3}=B_{a g g r}+W^{n e t} \Delta_{2}\left(1-\chi^{\frac{k-\beta}{k}}\right),
$$

which implies $Q^{3}\left(c_{3}\right)=\bar{I}^{3} / I<1$.

\section{A.3.4. Fourth Segment}

The cumulative income of all unemployed individuals, all employed active workers at firms producing for the domestic market and employed active workers at firms with a productivity level up to $\check{\phi} \in\left[\phi_{x}^{*}, \infty\right]$, i.e., exporting firms, is given by:

$$
I^{4}(\check{\phi})=\bar{I}^{3}+\left(1-t_{w}-t_{p w}\right)\left(1+\tau^{1-\sigma}\right) \frac{M}{1-G_{\phi}\left(\phi^{*}\right)} \kappa \int_{\phi_{x}^{*}}^{\check{\phi}} r(\phi) d G_{\phi}(\phi),
$$

where we use $h_{t}=\left(1+\tau^{1-\sigma}\right) h$. Executing the same steps as for the third segment, as well as using Equation (A.4), we arrive at:

$$
I^{4}(\check{\phi})=\bar{I}^{3}+W^{n e t} \Delta_{2}\left(\chi+\chi^{\frac{k-\beta}{k}}\right)\left(1-\left(\frac{\check{\phi}}{\phi_{x}^{*}}\right)^{\beta-k}\right) .
$$

The proportion of individuals that receives this income is given by:

$$
\eta(\check{\phi})=\frac{L^{l}+L^{u}+H \Delta_{4}}{\bar{L}}+\left(1-\tau^{1-\sigma}\right) \frac{1}{\bar{L}} \frac{M}{1-G_{\phi}\left(\phi^{*}\right)} \int_{\phi_{x}^{*}}^{\check{\phi}} h(\phi) d G_{\phi}(\phi) .
$$


Using $h(\phi)=\left(\phi / \widetilde{\phi}_{t}\right)^{\beta-\alpha \omega} \widetilde{h}$ and the Pareto distribution, we can rewrite the last expression as:

$$
\begin{gathered}
\eta(\check{\phi})=\frac{L^{l}+L^{u}}{\bar{L}}+\frac{H}{\bar{L}}\left[\Delta_{4}+\Delta_{5}\left(1-\left(\frac{\check{\phi}}{\phi^{*}}\right)^{\beta-\alpha \omega-k}\right)\right], \\
\Delta_{5} \equiv \frac{\chi^{\frac{k+\alpha \omega}{k}}+\chi^{\frac{k+\alpha \omega-\beta}{k}}}{\Delta_{3}}
\end{gathered}
$$

Combining Equations (A.21) and (A.22) to eliminate $\check{\phi}$, we find:

$$
\begin{gathered}
I^{4}\left(\eta, s, t_{w}, t_{p w}, t_{\pi}\right)=\bar{I}^{3}+W^{n e t} \Delta_{2}\left(\chi+\chi^{\frac{k-\beta}{k}}\right) \Omega_{3}(\eta), \\
\Omega_{3}(\eta) \equiv 1-\left(1-\left(\frac{\bar{L}}{H} \frac{1}{\Delta_{5}}\left(\eta-\frac{L^{l}+L^{u}}{\bar{L}}\right)-\frac{\Delta_{4}}{\Delta_{5}}\right)\right)^{\frac{\beta-k}{\beta-\alpha \omega-k}},
\end{gathered}
$$

such that the fourth segment of the Lorenz curve is given by:

$$
Q^{4}\left(\eta, s, t_{w}, t_{p w}, t_{\pi}\right)=\frac{I^{4}\left(\eta, s, t_{w}, t_{p w}, t_{\pi}\right)}{I} .
$$

In addition, we find $\eta(\check{\phi} \rightarrow \infty)=1$ and $I^{4}(1)=B_{\text {aggr }}+W^{\text {net }}$. Note that if UB are financed by a wage or a payroll tax (see Section 3.3), the budget constraint ensures that $B_{\text {aggr }}+W^{\text {net }}=W$, which equals aggregate income $I$ (see Equation (36)). Therefore, we obtain $Q^{4}(1)=1$. However, if UB are financed by a profit tax, we obtain $B_{a g g r}+W^{n e t}=B_{a g g r}+W>I$. This result is driven by the fact that we have ignored aggregate profits in our definition of income. To circumvent problems, we redefine income in this case as $I=W+T_{\pi}$, such that (by the budget constraint) $Q^{4}(1)=1$ holds.

\section{A.4. Robustness Checks}

\section{A.4.1. Main Specification}

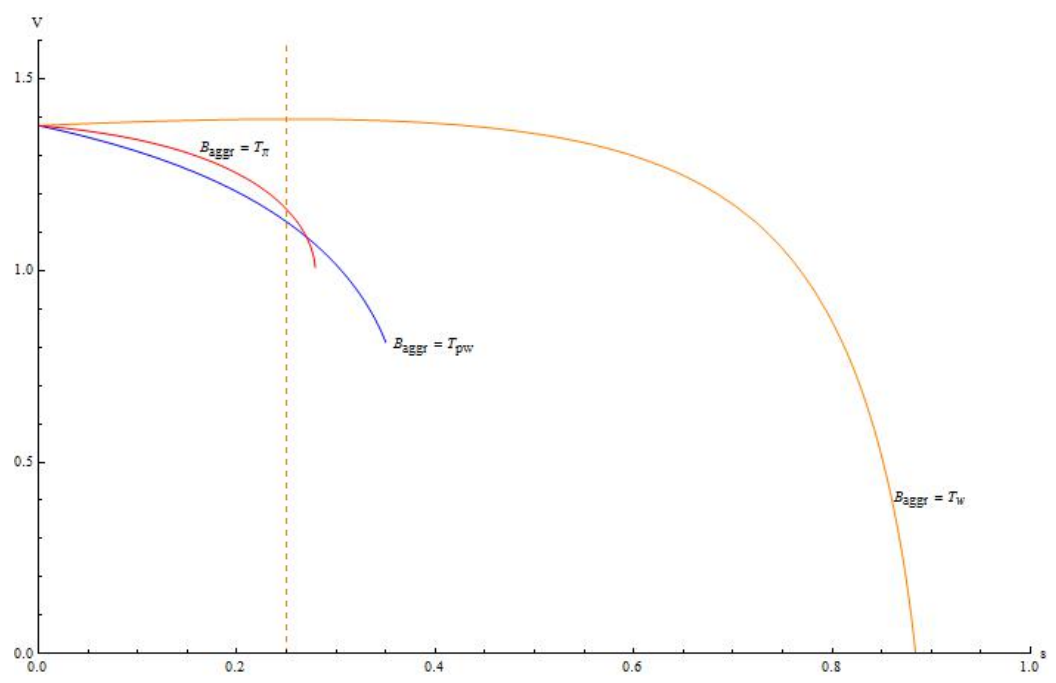

Figure A1. Optimal Redistribution I. 
A.4.2. Optimal Redistribution for Different Trade Costs

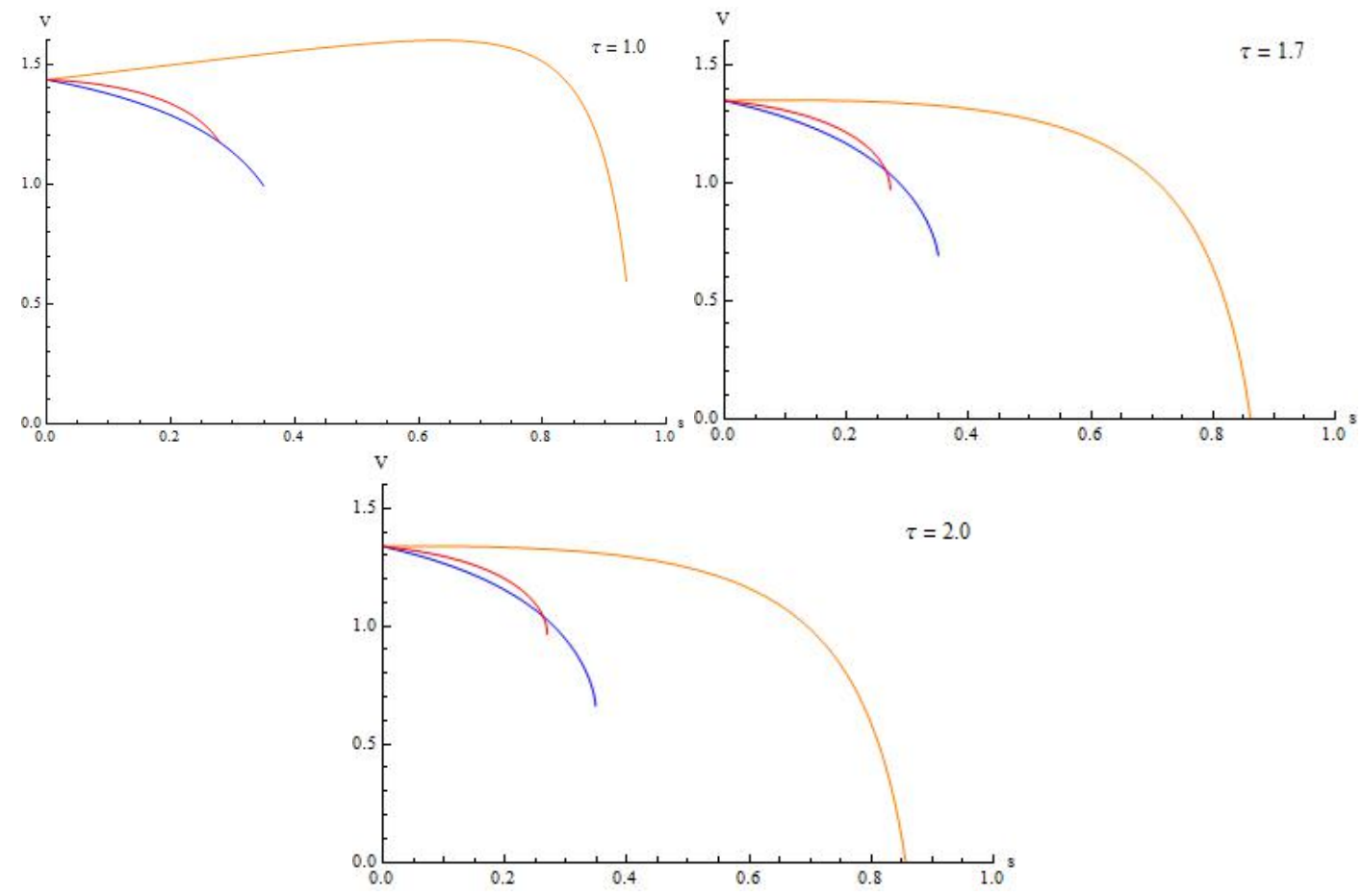

Figure A2. Optimal Redistribution II.

A.4.3. Optimal Redistribution for Different Inequality Aversions

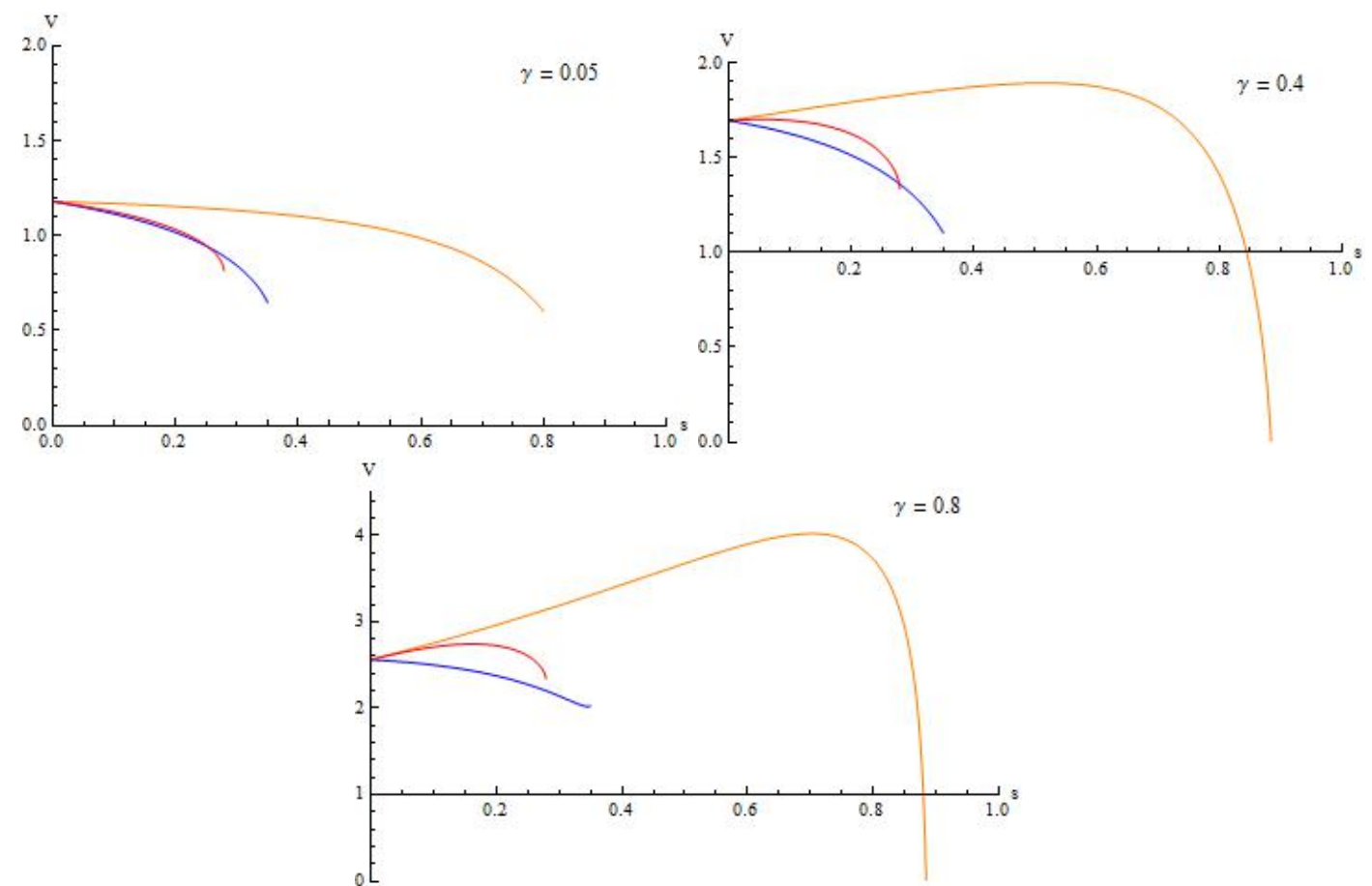

Figure A3. Optimal Redistribution III. 


\section{References}

1. Melitz, M.J. The impact of trade on intra-industry reallocations and aggregate industry productivity. Econometrica 2003, 71, 1695-1725.

2. Eaton, J.; Kortum, S.; Kramarz, F. An Anatomy of International Trade: Evidence from French Firms. Econometrica 2011, 79, 1453-1498.

3. Autor, D.H.; Dorn, D.; Hanson, G.H.; Song, H. Trade Adjustment: Worker-Level Evidence. Q. J. Econ. 2014, 129, 1799-1860.

4. Biscourp, P.; Kramarz, F. Employment, skill structure and international trade: Firm-level evidence for France. J. Int. Econ. 2007, 72, 22-51.

5. OECD. Growing Unequal? Income Distribution and Poverty in OECD Countries; Organization for Economic Co-operation and Development: Paris, France, 2009.

6. Scheve, K.F.; Slaughter, M.J. A new deal for globalization. Foreign Aff. 2007, 86, 34.

7. D'Ambrosio, C.; Frick, J.R. Individual wellbeing in a dynamic perspective. Economica 2012, 79, 284-302.

8. Engelmann, D.; Strobel, M. Inequality aversion, efficiency, and maximin preferences in simple distribution experiments. Am. Econ. Rev. 2004, 94, 857-869.

9. Fehr, E.; Schmidt, K.M. A theory of fairness, competition, and cooperation. Q. J. Econ. 1999, 114, 817-868.

10. Venn, D. Legislation, Collective Bargaining and Enforcement; OECD Publishing: Paris, France, 2009.

11. De Pinto, M. Redistribution of Trade Gains in the Presence of Firm and Worker Heterogeneity. World Econ. 2015, doi:10.1111/twec.12315.

12. De Pinto, M.; Michaelis, J. International Trade and Unemployment-The Worker-selection Effect. Rev. Int. Econ. 2014, 22, 226-252.

13. Helpman, E.; Itskhoki, O.; Stephen Redding, S. Inequality and unemployment in a global economy. Econometrica 2010, 78, 1239-1283.

14. Helpman, E.; Itskhoki, O.; Stephen Redding, S. Unequal effects of trade on workers with different abilities. J. Eur. Econ. Assoc. 2010, 8, 421-433.

15. Carlsson, F.; Daruvala, D.; Johansson-Stenman, O. Are People Inequality-Averse, or Just Risk-Averse? Economica 2005, 72, 375-396.

16. Lommerud, K.E.; Sandvik, B.; Straume, O.R. Good Jobs, Bad Jobs and Redistribution. Scand. J. Econ. 2004, 106, 703-720.

17. Egger, H.; Kreickemeier, U. Redistributing gains from globalisation. Scand. J. Econ. 2009, 111, $765-788$.

18. Egger, H.; Kreickemeier, U. Fairness, trade, and inequality. J. Int. Econ. 2012, 86, 184-196.

19. Dixit, A.; Norman, V. Gains from trade without lump-sum compensation. J. Int. Econ. 1986, 21, 111-122.

20. Brecher, R.A.; Choudhri, E.U. Pareto gains from trade, reconsidered: Compensating for jobs lost. J. Int. Econ. 1994, 36, 223-238. 
21. Itskhoki, O. Optimal Redistribution in an Open Economy. Available online: https://www.princeton.edu/itskhoki/papers/RedistributionOpen.pdf 22 October 2015).

22. Egger, H.; Kreickemeier, U. Firm heterogeneity and the labor market effects of trade liberalization. Int. Econ. Rev. 2009, 50, 187-216.

23. Booth, A. A public choice model of trade union behaviour and membership. Econ. J. 1984, 94, 883-898.

24. OECD. Benefits and Wages 2007; Organization for Economic Co-operation and Development: Paris, France, 2007.

25. Fairris, D.; Jonasson, E. What accounts for intra-industry wage differentials? Results from a survey of establishments. J. Econ. Issues 2008, 42, 97-114.

26. Holmlund, B.; Zetterberg, J. Insider effects in wage determination: Evidence from five countries. Eur. Econ. Rev. 1991, 35, 1009-1034.

27. Layard, R.; Stephen Nickell, S. Is unemployment lower if unions bargain over employment? Q. J. Econ. 1990, 105, 773-787.

28. Layard, P.R.G.; Nickell, S.J.; Jackman, R. Unemployment: Macroeconomic Performance and the Labour Market; Oxford University Press: Oxford, UK, 2005.

29. Lambert, P. The Distribution and Redistribution of Income: A Mathematical Analysis; Manchester University Press: England, UK, 1993.

30. Amiel, Y.; Creedy, J.; Hurn, S. Measuring attitudes towards inequality. Scand. J. Econ. 1999, 101, 83-96.

31. De Pinto, M. International Trade and Unemployment: On the Redistribution of Trade Gains When Firms Matter; Springer-Verlag Berlin Heidelberg: Berlin, Germany, 2013.

32. Felbermayr, G.; Prat, J.; Schmerer, H.-J. Globalization and labor market outcomes: Wage bargaining, search frictions, and firm heterogeneity. J. Econ. Theory 2011, 146, 39-73.

33. Ghironi, F.; Melitz, M. International Trade and Macroeconomic Dynamics with Heterogeneous Firms. Q. J. Econ. 2005, 120, 865-915.

34. Balistreri, E.J.; Hillberry, R.J.; Rutherford, T.F. Structural estimation and solution of international trade models with heterogeneous firms. J. Int. Econ. 2011, 83, 95-108.

35. Keane, M.P. Individual heterogeneity and interindustry wage differentials. J. Hum. Resour. 1993, 28, 134-161.

36. Schwarze, J.; Härpfer, M. Are people inequality averse, and do they prefer redistribution by the state? Evidence from german longitudinal data on life satisfaction. J. Soc. Econ. 2007, 36, 233-249.

(c) 2015 by the author; licensee MDPI, Basel, Switzerland. This article is an open access article distributed under the terms and conditions of the Creative Commons Attribution license (http://creativecommons.org/licenses/by/4.0/). 